\title{
Decision-Making Methodologies for Reuse of Industrial Assets
}

\author{
J. Claver (iD, A. García-Domínguez, and M. A. Sebastián \\ Department of Construction and Manufacturing Engineering, Universidad Nacional de Educación a Distancia (UNED), \\ C/Juan del Rosal 12, 28040 Madrid, Spain \\ Correspondence should be addressed to J. Claver; jclaver@ind.uned.es
}

Received 2 November 2017; Revised 15 December 2017; Accepted 3 January 2018; Published 7 February 2018

Academic Editor: Julio Blanco-Fernández

Copyright (C) 2018 J. Claver et al. This is an open access article distributed under the Creative Commons Attribution License, which permits unrestricted use, distribution, and reproduction in any medium, provided the original work is properly cited.

\begin{abstract}
When there is a social consensus that industrial assets are in fact heritage elements of cultural interest, their conservation and reuse must be considered with approaches that offer greater guarantees and that prevent their exposure to aggressive actions. In order for this to materialise, many aspects must be included in the decision-making process, from the characteristics of an asset and its surroundings, to the valuable aspects that distinguish it and that must be protected. This study aims to develop tools that guide the decision-making process regarding the most appropriate activity for each specific case study. Multicriteria Decision Support Techniques are evaluated as adequate support to create a proposal that fulfils these objectives. Furthermore, the Analytic Hierarchy Process is adapted to develop methodologies for assessing both the heritage value and the most compatible uses according to the characteristics of the asset. Subsequently, they are connected and such considerations regarding the heritage value of the asset are incorporated into the final decision. The tools developed are then applied to a case study to test their performance, assess their usefulness, and identify possible applications and future developments.
\end{abstract}

\section{Introduction}

If it is accepted that industrial assets have heritage value, an increasingly widespread social perception, their conservation must be addressed. However, the conservation of something valuable must be respectful of that value, making it necessary to clearly identify its constituent parts. What is more, if you have a broad sample of the same type of assets to be conserved, the most important ones must be identified, as conserving the whole sample is not viable. If the original function of those elements has finalised and urban development in recent decades has left them out of place in their surroundings, such elements will require a new function that makes their long-term conservation viable. This new function, which the assets were not designed for and which will require certain adaptation, presents a risky scenario regarding the possible aggression that said adaptation may entail for their valuable characteristics [1].

Therefore, the adequate reuse of these types of heritage assets of cultural interest creates a scenario in which many aspects must be jointly considered. There are many examples of the reuse for new activities of these types of assets that have led to the total destruction of everything that provided an understanding of the production processes they once accommodated. Industrial heritage illustrates our technological, production, and social evolution through the processes, equipment, and systems to which it bears witness. The aim of this study is to develop tools that guide the decision-making process of the most appropriate activity for each specific case, avoiding the threat that many reuse actions entail for these assets.

In this context, Multicriteria Decision Support Techniques can offer the necessary support for the incorporation of structures of criteria that contemplate the different aspects to be considered and their simultaneous integration as decision factors [2,3]. Multicriteria Decision Support Techniques have been extensively studied and applied over recent years in very different approaches with equally varied objectives. These techniques have been widely applied in the industrial field in recent decades. Project management [4], definition of policies and strategies [5-7], engineering of manufacturing processes [8], and material selection [9] are some of the scenarios in which these techniques have been present. However, their flexibility allows them to be applied in many 
other and very different contexts, such as the world of sport [10]. In today's complex world, where decisions in any field are influenced by many interrelated aspects and conditions, the interest and usefulness of these techniques are clear.

In the context of this study, the new use decision must consider the characteristics of the asset, ensuring its capacity to accommodate the needs' programme of the new activity. Furthermore, the characteristics of the setting, assessing the possible demand for the uses considered as alternatives and their suitability for the location, and the potential cultural value of the asset to protect its constituent parts-restricting their modification during the adaptation to the new use-must be taken into account. Incorporating the heritage value into the decision-making process is the ultimate objective of this study. The nature of the aspects to be considered is therefore rather varied. Morphological aspects of the asset and technological-scientific aspects of cultural value, both tangible and intangible, are included.

After analysing and evaluating different Multicriteria Decision Support Techniques, the Analytic Hierarchy Process (AHP), developed by Professor Thomas Saaty in the late 1970s, was selected for this study [11, 12]. Over the years, this technique has been applied to studying different contexts where a range of aspects have to be jointly considered in the decision-making process. Extensive scientific work has resulted from this in recent decades.

The application of the AHP as a tool for the analysis and management of industrial heritage assets is new. It is possible, however, to identify previous application initiatives in fields with certain synergies that may serve as a reference. This is the case of building renovations, from both sustainability and energy efficiency perspectives $[13,14]$, and of historical and cultural heritage asset protection [14-16]. The assessment of property and industrial land has also been approached through the application of this technique [17]. In previous studies, the authors made the first attempts to apply the AHP in selecting new uses for these types of assets [18]. This study rectifies the deficiencies of the previous proposals and puts forward an effective methodology, which was validated with real case study application.

The software selected and used in this work was Microsoft Excel, due to the need for flexibility in the various stages of the work. Thus, the multicriteria structures designed and the matrices associated to them were developed by using this tool. The interface of the datasheets of results and all the graphs included in them were also designed using this software. And thanks to this common support, these graphs are automatically generated when users introduce information about a particular study case into the multicriteria structures of the proposed methodology. Thus, using a single tool, all the needs of the proposed methodologies are covered.

\section{Proposed Methodology}

During the selection of the most appropriate decision support technique, the suitability of the Analytic Network Process (ANP) was considered as an alternative for carrying out this study $[19,20]$. However, the possible presence, or not, of cultural and heritage value characteristics in the industrial assets analysed does not affect its new use suitability for housing another activity. The morphological characteristics of the asset determine its capacity to accommodate a specific use. The independence of both criteria, heritage and morphological characteristics, and the interest of being able to analyse both aspects separately and jointly led to the AHP being selected for this study.

The application of the AHP to achieve the objectives established in the study requires an adaptation. The hierarchical structure of criteria of this method means that the impact of the heritage value cannot be directly incorporated into the final decision. A methodology based on three partial developments with different objectives, which can work both independently and jointly, is proposed. The ultimate objective is the incorporation of the heritage value in the selection of new uses, choosing the least aggressive or most respectful ones as regards said value. But this final objective creates preliminary objectives. To protect the value of an asset, identifying the parts containing those singular characteristics and the intensity of such value is required. The singularity of an asset is implicitly associated with its singularity within the sample of elements of the same type. It is therefore necessary to have a sufficiently representative sample of assets that have been properly analysed. Figure 1 shows the structure of the global methodology proposed and the partial methodologies comprising it.

The first of the partial methodologies develops an extensive field of study to identify a large sample of industrial assets in the territory focused on: Spain. As such, a catalogue has been prepared that includes 49 classification criteria applied to all of the assets identified. This makes it possible to contextualise each particular asset in a sample and to perform varied analyses according to common characteristics such as type, production sector, and new use. The analysis of the sample at territory level, not just nationally but also in smaller territories, is another of outcome of interest offered by this part of the methodology [1,21], enabling the characterisation of this type of heritage in different territories. The number of assets currently included in the catalogue produced by the authors exceeds 1500 elements.

Once knowledge of the sample of assets is guaranteed, work will start on studying specific assets: firstly relating to their heritage assessment, based on their cultural value, and then to the selection of the use, the adaptation of which being more respectful of or less aggressive on the value identified. As indicated in Figure 1, this is where the adaptation of the AHP as a Multicriteria Decision Support Tool comes into play. Thus, independent structures of criteria are defined for each partial methodology. These are subsequently connected to each other, based on the relationships between some of the criteria of both structures. Both structures of criteria and their connection are described below.

2.1. Structure of Criteria for the Heritage Assessment of the Assets Analysed. The first step in the assessment of the heritage or cultural value of an industrial asset is to identify the characteristics that can contain said value. This entails identifying the asset aspects that have the greatest capacity to contain knowledge and to transmit it through observation 


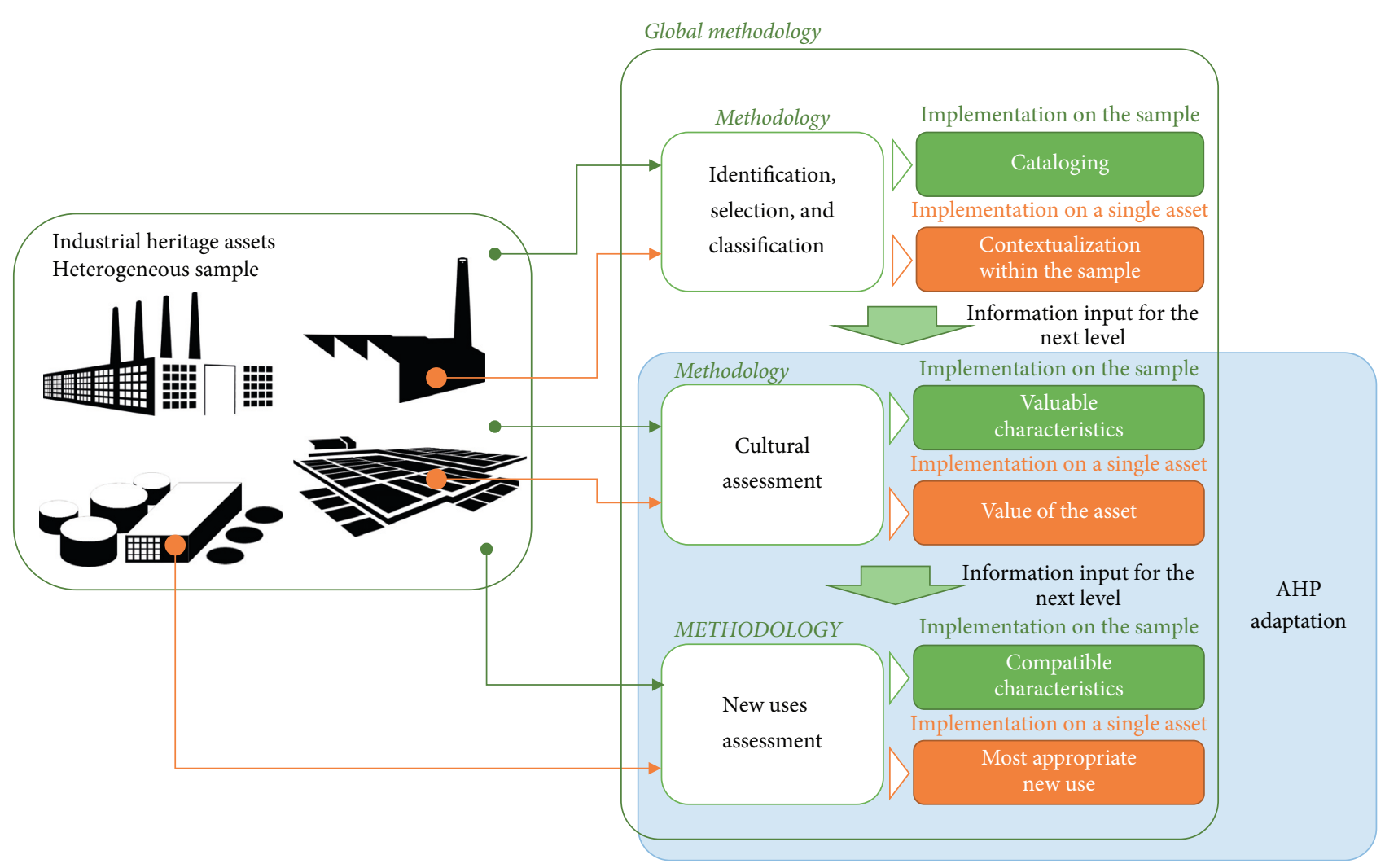

FIGURE 1: Integration of the partial methodologies in the global methodology proposed.

of the places they are in. These types of assets are valuable and representative from different perspectives, which is why the characteristics to consider are of a very varied nature. The role of these assets in technological and production development is evident. However, they also play a key role in social development today, from economic, demographic, social, territorial, and urban points of view. Similarly, as real property, their technical and formal quality must be taken into account, as well as their conception in relation to requirements and processes accommodated.

The AHP enables simultaneous consideration of the different types of value characteristics, understanding them as the criteria considered for the analysis to be performed. The characteristics to be considered allow gradual phasing. In other words, aspects of a certain nature that must be considered can be identified and, within them, other more specific aspects for each case too. The structure of criteria will therefore have different levels, corresponding to the classical structure of the AHP $[11,12]$, in which the criteria and subcriteria considered will be distributed. Table 1 shows the criteria and subcriteria considered initially for the assessment of the heritage value of the industrial assets. A brief description of the criterion considered is included in each case.

Two initial criteria levels are therefore established and identified as CR1 and CR2. All these aspects are included in the heritage value assessment of the assets analysed. However, not all of them will have the same importance. As previously stated, situations were identified in which actions to reuse industrial assets would mean the disappearance of aspects that best connect them to the original production activity. Moreover, those actions would destroy the parts that best illustrate the production process that justifies the existence of the assets and their capacity to transmit the corresponding knowledge. The aim of this study is to avoid these situations. Therefore, without discounting any type of characteristic, the aspects that best connect to the industrial activity are prioritised. Such an approach is also logical if we are talking about an industrial type of heritage.

Therefore, pairwise comparisons are made using the Saaty fundamental scale $[11,12]$ shown in Table 2 . These judgements estimate the importance or contribution of criteria in relation to the objectives, which, in this case, relate to the singularity of the asset analysed. This scale considers values from 1 to 9, which range from the same level of importance or preference, to very strong dominance by one criterion over another. Intermediate values can be used when necessary, as well as inverse values when the dominance is in the opposite direction.

Considering the Saaty scale values, pairwise comparisons are made between the criteria of each level, making judgements on the importance that one criterion has compared to another in relation to the higher level of the structure. For CR1 criteria, this means the extent to which singularity is contributed to the asset. For CR2 criteria, the comparison 
TABLE 1: Heritage assessment criteria.

CR1-1. Technological singularity

The asset has production technologies of special interest, especially focused on machinery

CR2-1. Technological exclusivity

Its installations and equipment represent unique or representative examples

CR2-2. Technological innovation

Its installations and equipment represented pioneering applications of a technology

\section{CR2-3. Layout}

The floor layout is meaningful and helps to understand the original production process

CR1-2. Functional singularity

The design of the asset has an interpretable and interesting relationship with the production process

\section{CR2-4. Sizing of spaces}

The design of the spaces in terms of area and height is representative and helps to understand the production process

\section{CR2-5. Fitting out of the spaces}

The design of the light and sanitation conditions of the spaces is representative and helps in understanding the original production process

\section{CR2-6. Structure}

The structural design is of special interest and helps in creating appropriate spaces for the production activities that it houses

CR1-3. Construction singularity

The asset is created with noteworthy construction and structural techniques
CR2-7. Construction technique

The construction techniques are of special interest

CR2-8. Architectural or artistic style

The asset and/or its parts have noteworthy architectural or artistic styles

CR2-9. Socioeconomic impact on the setting

It has significantly impacted the demographic, social, or economic development of its setting, where it may be possible to identify other elements related to it

CR2-10. Production tradition

It is included in a production activity rooted in the territory and in its cultural memory

CR2-11. Antiquity

Belongs to a historical period that gives it added value due to the scarcity of examples today

CR1-5. Production singularity

The asset represents an unusual production activity in its setting

TABLE 2: Saaty fundamental scale $[11,12]$.

\begin{tabular}{lcc}
\hline Numerical scale & Verbal scale & Explanation \\
\hline (1) & Equal importance or preference & Both criteria contribute in equal measure to the objectives \\
$(2)$ & Slight importance or preference & \\
$(3)$ & Moderate importance or preference & One criterion is prioritised moderately over another \\
$(4)$ & Moderate plus & \\
$(5)$ & Strong importance or preference & One criterion is prioritised strongly over another \\
$(6)$ & Strong plus & \\
$(7)$ & Very strong importance or preference & One criterion is prioritised very strongly over another \\
$(8)$ & Very, very strong & \\
$(9)$ & Extremely strong importance or preference & Prioritisation reaches the highest value possible \\
\hline
\end{tabular}

is made in reference to the contribution of value from the singularity of CR1 criteria with which the compared CR2 criteria are associated.

These pairwise comparisons are used to create the judgement matrices, which establish the preferences between criteria defined by the decision-makers. Figure 2(a) shows the matrix that contains the judgements made when making comparisons between CR1 criteria regarding the first level of the structure of criteria. The selected way to derive the priority vector from this matrix is the eigenvalue formulation [12]. The solution is obtained by raising the matrix to a sufficiently large power. In this case the process returns 


\begin{tabular}{|l|c|c|c|c|c|}
\cline { 2 - 6 } \multicolumn{1}{c|}{} & CR1-1 & CR1-2 & CR1-3 & CR1-4 & CR1-5 \\
\hline CR1-1 & 1,0000 & 1,0000 & 5,0000 & 3,0000 & 3,0000 \\
\hline CR1-2 & 1,0000 & 1,0000 & 5,0000 & 3,0000 & 3,0000 \\
\hline CR1-3 & 0,2000 & 0,2000 & 1,0000 & 0,3333 & 0,3333 \\
\hline CR1-4 & 0,3333 & 0,3333 & 3,0000 & 1,0000 & 1,0000 \\
\hline CR1-5 & 0,3333 & 0,3333 & 3,0000 & 1,0000 & 1,0000 \\
\hline
\end{tabular}

$\lambda=5,0556$

a)

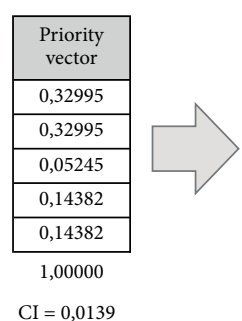

$\mathrm{CI}=0,0139$

\begin{tabular}{|c|c|c|c|c|c|}
\cline { 2 - 6 } \multicolumn{1}{c|}{} & CR1-1 & CR1-2 & CR1-3 & CR1-4 & CR1-5 \\
\hline CR1-1 & $3,6233 E+10$ & $3,6233 E+10$ & $2,3205 E+11$ & $9,6460 E+10$ & $9,6460 E+10$ \\
\hline CR1-2 & $3,6233 E+10$ & $3,6233 E+10$ & $2,3205 E+11$ & $9,6460 E+10$ & $9,6460 E+10$ \\
\hline CR1-3 & $5,8109 E+09$ & $5,8109 E+09$ & $3,7214 E+10$ & $1,5470 E+10$ & $1,5470 E+10$ \\
\hline CR1-4 & $1,3610 E+10$ & $1,3610 E+10$ & $8,7163 E+10$ & $3,6233 E+10$ & $3,6233 E+10$ \\
\hline CR1-5 & $1,3610 E+10$ & $1,3610 E+10$ & $8,7163 E+10$ & $3,6233 E+10$ & $3,6233 E+10$ \\
\hline
\end{tabular}

$\mathrm{CR}=0,0124$

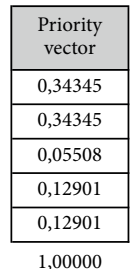

1,00000

Figure 2: Matrices of priorities for CR1 criteria.

equivalent results for the components of the priority vector in the third and fourth iteration. The process then finishes and the priority vector indicated in Figure 2(b) is obtained.

During the formulating process of these matrices, the consistency of the judgements of the decision-makers is verified. Saaty establishes two parameters to assess each aspect [12]. The first one is the consistency index of the comparison matrix, which is given by $\mathrm{CI}=\left(\lambda_{\max }-n\right) /(n-$ 1 ), where $\lambda_{\max }$ is the eigenvalue of the matrix and $n$ is the matrix range. Then the consistency ratio (CR) is obtained by comparing the CI with the corresponding value of the ones indicated in Table 3. The obtained value must be less than 0.10 ; otherwise the judgements must be reviewed.

The process is repeated in a similar manner for the judgement matrices for the second-level CR2 criteria. This leads to the distribution of weights for the CR1 and CR2 criteria shown in the upper part of Figure 3.

As shown, the structure of criteria of Figure 3 includes a new CR3 criteria level. The weights of the characteristics identified in the higher levels are constant for any asset analysed applying the proposed methodology. This will guide the assessment in making preferences regarding the aspects considered to be of greatest value, which in this case are those that best illustrate the original production process. However, although the importance of these characteristics, in terms of the approach, will be constant for any asset analysed, their presence will vary in each particular case study. Thus, the preferencing of criteria related to the value of the machinery has a greater starting weight than the artistic value, but the case may be that in one study all the machinery is kept, while, in another, it has disappeared. Therefore, all the characteristics represented by CR2 criteria must be scored for each specific case study analysed, with such need subsequently giving rise to the new CR3 criteria level.

The question is how to undertake the assessment or scoring of each characteristic contained in CR2 criteria. For this, there are three aspects or criteria to be considered. The first refers to the intensity of the importance or value that that characteristic has in that specific asset. The second refers to the current state of the asset in relation to said characteristic, which dramatically influences the current capacity of the element to transmit the associated knowledge. The third regards the geographical singularity of the asset in relation to that characteristic. If there are similar examples in its territory, this singularity will be less than in cases in which it represents a unique or infrequent example. Of the three aspects incorporated in this new criteria level, the last two may vary over time and the scores will therefore change: the current state due to the degradation of the asset or its renovation, and geographical singularity when similar examples in the area disappear.

Furthermore, the impact of these aspects, such as the current state, does not affect all the characteristics considered in the CR2 criteria in the same way. For example, the loss of parts of the machinery can significantly affect its capacity to illustrate how it functioned. However, the degradation of roofs, enclosures, and other elements of the building have much less of an effect on the capacity to interpret the size of the spaces or floor layout, as can be seen when visiting abandoned factories in a state of ruin. Therefore, the comparison matrices for CR3 criteria, in relation to each of the CR2 criteria, are compiled in a similar way to the previous levels.

This is where the static part of this first partial methodology ends, with the weights of the CR1, CR2, and CR3 criteria established for any industrial asset analysed. As such, each CR3 referring to a CR2 will be scored, based on an assessment by a qualified technician during the physical visit to the asset. To consider the proposed methodologies as work tools was one of the objectives of this study, facilitating their use and maximising their potential impact.

As shown in Figure 3, in this first adaptation of the classical structure, the AHP alternatives are not included. The hierarchical criteria structure is established to provide a hierarchy of the different characteristics, which can give the asset singularity and result in it being deemed of cultural interest within this typology. From that common structure for any element analysed, and the scores given for a specific case study, a reading is obtained of the heritage value of the asset and the weighted distribution of that value between the different characteristics in the different levels of the structure. Figure 3 illustrates this distribution of weights within the hierarchical structure based on scores introduced by way of example. This allows for different analyses which will be explained in subsequent sections.

2.2. Structure of Criteria for Selection of New Uses. To select a new use, we propose the compatibility criterion that the authors used in previous studies, where they started to explore the possibilities of the multicriteria methods for analysis and management of these assets [18]. Adaptation 


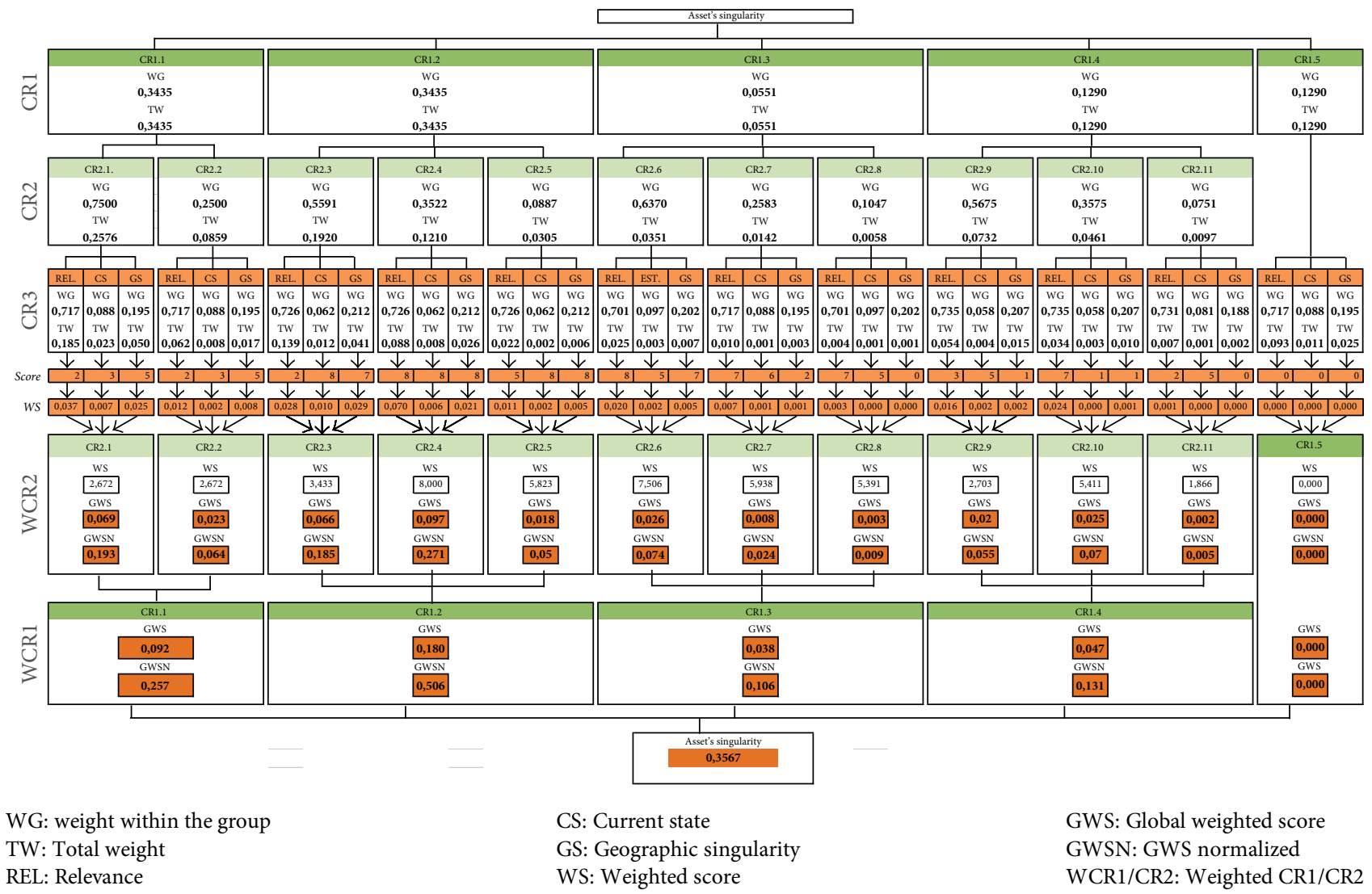

FIGURE 3: Structure of criteria for the heritage assessment of the assets.

TABLE 3: Average random consistency index (RI) [11, 12].

\begin{tabular}{|c|c|c|c|c|c|c|c|c|c|c|}
\hline$N$ & $(1)$ & $(2)$ & $(3)$ & $(4)$ & $(5)$ & $(6)$ & $(7)$ & $(8)$ & $(9)$ & $(10)$ \\
\hline Random consistency index (RI) & 0 & 0 & 0.52 & 0.89 & 1.11 & 1.25 & 1.35 & 1.40 & 1.45 & 1.49 \\
\hline
\end{tabular}

to the new activity will have an impact on the asset. Based on that idea, the objective is to minimise the impact on characteristics that have heritage value. In practice, this is channelled in two ways: on the one hand, activities that require less adaptation of the asset will be of more interest; and, on the other, adaptations that affect parts of the element without any associated value will be acceptable, although those that affect parts with value will be restricted. This means that it is possible to talk about the analysis of two types of compatibility. On the one hand, direct compatibility is associated with the capacity of the asset analysed to accommodate the activities considered as alternative activities based on their morphological characteristics. And, on the other, modification is accepted in indirect compatibility, but not of the parts that have heritage value.

2.2.1. Direct Compatibility without Consideration of the Heritage Value. The criteria structure to consider must first be defined. Two types of criteria are considered in this study. The first regards the morphological characteristics of the asset, which help in characterising its spaces and its capacity to accommodate new use activities. The second regards the institutional density of uses considered as alternatives in the setting of the asset analysed, in order to identify the level of current demand and possible synergies. The uses are considered as alternatives, derived from the asset reuse actions identified in the first of the partial methodologies undertaken by the authors in prior studies [1,21]. Table 4 shows both the criteria and uses considered as alternatives.

The comparison matrices are compiled for the criteria of each level of the structure in the same way as in the partial methodology for the heritage assessment of assets. In the first level, whose criteria are identified as CR4 criteria, a strong priority of the characteristics of the asset is indicated as opposed to those of the setting, as these are the ones that indicate compatibility. A higher degree of preference to help ensure that the activity is better attuned to its setting and that the selection is successful has not been opted for.

As regards the next level's criteria, identified as CR5 criteria, equal weights or importance are established, regarding all the criteria in the corresponding group, for both the criteria associated with the asset and those associated with the setting. None have preference over others and, as such, the matrices are symmetrical, with all the values equal to the unit. The 
TABLE 4: Criteria and uses considered in the hierarchical structure to select new uses.

\begin{tabular}{|c|c|}
\hline \multirow{11}{*}{$\begin{array}{l}\text { CR4-1. } \\
\text { Characteristics } \\
\text { of the asset }\end{array}$} & CR5-1. Large area occupied by machinery \\
\hline & CR5-2. Machinery in good aesthetic condition \\
\hline & CR5-3. Machinery in good working order \\
\hline & CR5-4. Made up of separate elements \\
\hline & CR5-5. Large open spaces (without pillars) \\
\hline & CR5-6. High ceiling open spaces (without pillars) \\
\hline & CR5-7. Large continuous spaces \\
\hline & CR5-8. High ceiling continuous spaces \\
\hline & CR5-9. High level of natural light \\
\hline & CR5-10. Linked to other elements of the setting \\
\hline & CR5-11. Has outdoor spaces \\
\hline \multirow{14}{*}{$\begin{array}{l}\text { CR4-2. } \\
\text { Characteristics } \\
\text { of the setting }\end{array}$} & CR5-12. High presence of USE 1 \\
\hline & CR5-13. High presence of USE 2 \\
\hline & CR5-14. High presence of USE 3 \\
\hline & CR5-15. High presence of USE 4 \\
\hline & CR5-16. High presence of USE 5.1 \\
\hline & CR5-17. High presence of USE 5.2 \\
\hline & CR5-18. High presence of USE 6 \\
\hline & CR5-19. High presence of USE 7 \\
\hline & CR5-20. High presence of USE 8 \\
\hline & CR5-21. High presence of USE 9 \\
\hline & CR5-22. High presence of USE 10 \\
\hline & CR5-23. High presence of USE 11 \\
\hline & CR5-24. High presence of USE 12.1 \\
\hline & CR5-25. High presence of USE 12.2 \\
\hline \multirow{14}{*}{ Uses } & Use 1. Administrative and offices \\
\hline & Use 2. Hotel and restaurant sector \\
\hline & Use 3. Sport \\
\hline & Use 4. Industrial heritage informative \\
\hline & Use 5.1. Educational \\
\hline & Use 5.2. Research \\
\hline & Use 6. Commercial \\
\hline & Use 7. Public space and green areas \\
\hline & Use 8. Industrial \\
\hline & Use 9. Religious \\
\hline & Use 10. Residential \\
\hline & Use 11. Health \\
\hline & Use 12.1. Social \\
\hline & Use 12.2. Cultural \\
\hline
\end{tabular}

aim of the structure considered is to analyse the compatibility of the morphological characteristics of an asset with those required by a series of uses for correctly accommodating the activities. The preference, therefore, for one characteristic or another is established based on the uses according to the criteria, that is, from the alternatives, which prioritise some characteristics over others. However, preferencing cannot be established beforehand for those characteristics. Having open spaces does not take preference over having a lot of machinery. It will depend on the future use. It is the new uses that establish that preference for one characteristic or another.

The presence of those characteristics in the asset and its setting will also be specific features of each particular case study. Each asset will stand out for having certain characteristics and for not having others. Thus, just as outlined in the previous section for the heritage assessment methodology, these characteristics must be scored for the asset analysed. It will therefore be the CR5 criteria scores, for both the criteria associated with the asset and those associated with the setting, which determine the weight that these criteria have within the structure for each particular asset. Weights which will be affected by the prioritisation carried out at the higher level, that is, the CR4 weight, are the ones in which greater importance was given to the group of criteria corresponding to the asset.

Finally, the demand made by the alternatives-that is, possible new uses-of each of the characteristics included in the CR5 criteria must be analysed. Therefore, the corresponding matrices of pairwise comparisons are compiled. This process is long and has guidelines and datasheets to assist decision-makers in the judgement-making process. A datasheet is prepared for each CR5, which analyses the demand regarding the characteristic corresponding to each use. For each alternative or use, three fields on the typologies, archetypes, and the programmes of usual needs in the buildings intended for that activity are included. Decisionmakers, therefore, are encouraged to reflect on these three aspects before making their assessment on the intensity of the demand that that use makes of the CR5 characteristic analysed. The intention is to differentiate between situations in which the characteristic is positive for the use and others in which it is vital. For example, open spaces free of obstacles may be appropriate for many activities due to the flexibility they provide. However, they may be vital for sports, especially as some disciplines require open spaces for specific activities. A clear differentiation must therefore be made in the demand for that characteristic in terms of both situations. These datasheets also aid the review of judgements made by decision-makers.

In addition, the construction of the 25 matrices that compare the demands of the 14 uses for each CR5 criterion involves making 91 comparisons per matrix, which means a total of 2,275 comparisons solely in this part of the study. This is an excessive task which diminishes the applicability of the proposed methodology and its intended field tool nature. Therefore, based on the 14 scores included in each datasheet on the demand that the uses make of each CR5 characteristic, the matrices are programmed for autocompletion. This reduces the 91 judgements per matrix to 14 .

The criterion shown in Table 5 is used to undertake it. Taking as a reference the main scores of the Saaty scale, that is, the odd ones, the scale could be considered to have four intervals. Thus, two preference or demand scores of the characteristic, which will be separated by two units, would be separated by a magnitude equivalent to one interval. The differences, therefore, associated with complete intervals are linked to the Saaty scale. Differences in the assessment equivalent to one interval, or to two units on the numerical 


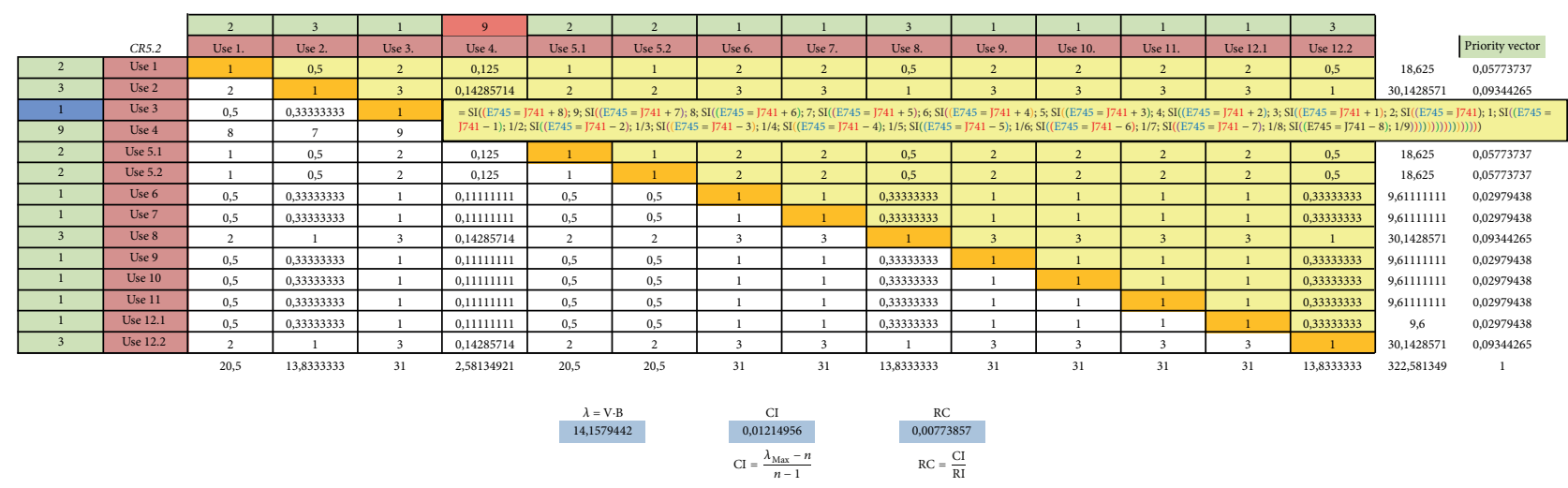

$=\operatorname{SI}((\mathrm{E} 745=\mathrm{J} 741+8) ; 9 ; \operatorname{SI}((\mathrm{E} 745=\mathrm{J} 741+7) ; 8 ; \operatorname{SI}((\mathrm{E} 745=\mathrm{J} 741+6) ; 7 ; \mathrm{SI}((\mathrm{E} 745=\mathrm{J} 741+5) ; 6 ; \operatorname{SI}((\mathrm{E} 745=\mathrm{J} 741+4) ; 5 ; \mathrm{SI}((\mathrm{E} 745=\mathrm{J} 741+3) ; 4 ; \operatorname{SI}((\mathrm{E} 745=\mathrm{J} 741+2) ; 3 ; \operatorname{SI}((\mathrm{E} 745=\mathrm{J} 741+1) ; 2 ; \mathrm{SI}((\mathrm{E} 745=\mathrm{J} 741) ; 1 ; \mathrm{SI}((\mathrm{E} 745=$ $\mathrm{J} 741$ - 1); 1/2; $\mathrm{SI}((\mathrm{E} 745=\mathrm{J} 741-2) ; 1 / 3 ; \mathrm{SI}((\mathrm{E} 745=\mathrm{J} 741$ - 3); 1/4; $\mathrm{SI}((\mathrm{E} 745=\mathrm{J} 741-4) ; 1 / 5 ; \mathrm{SI}((\mathrm{E} 745=\mathrm{J} 741$ - 5); $1 / 6 ; \mathrm{SI}((\mathrm{E} 745=\mathrm{J} 741$ - 6); $1 / 7 ; \mathrm{SI}((\mathrm{E} 745=\mathrm{J} 741-7) ; 1 / 8 ; \mathrm{SI}((\mathrm{E} 745=\mathrm{J} 741-8) ; 1 / 9)))))))))))))))$

(a)

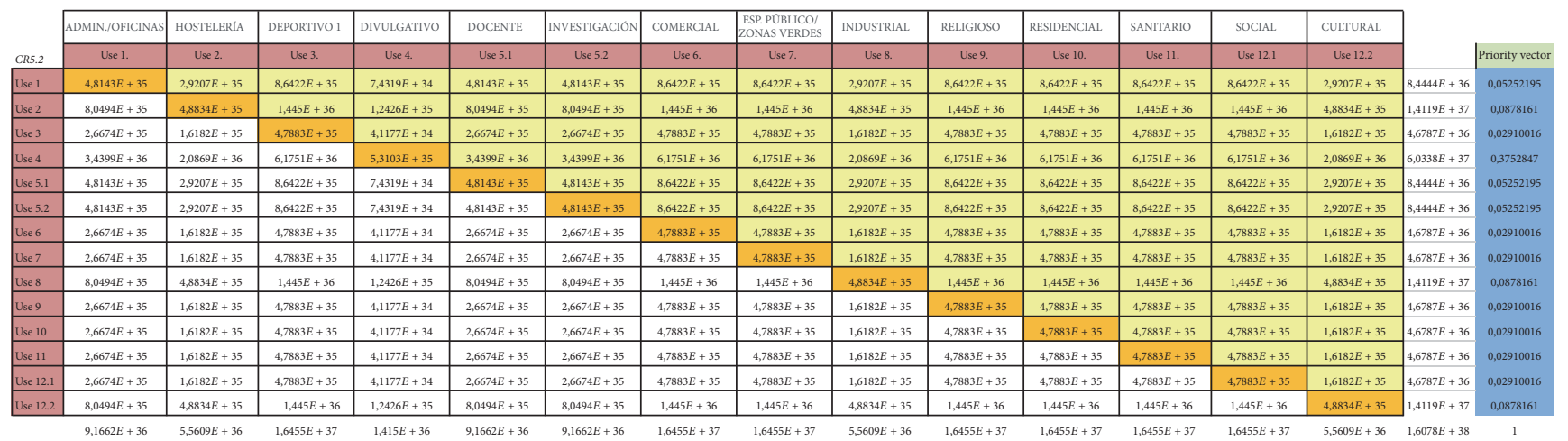

(b)

FIGURE 4: Formulation of the cells of the matrices in Excel.

TABLE 5: Criteria for comparing assessments of the demand for CR5 criteria from the uses for automation of judgements.

\begin{tabular}{|c|c|c|c|c|c|c|c|c|}
\hline & 9 & 8 & 7 & 6 & 5 & 4 & 3 & 2 \\
\hline 9 & 1 & 2 & 3 & 4 & 5 & 6 & 7 & 8 \\
\hline 8 & $1 / 2$ & 1 & 2 & 3 & 4 & 5 & 6 & 7 \\
\hline 7 & $1 / 3$ & $1 / 2$ & 1 & 2 & 3 & 4 & 5 & 6 \\
\hline 6 & $1 / 4$ & $1 / 3$ & $1 / 2$ & 1 & 2 & 3 & 4 & 5 \\
\hline 5 & $1 / 5$ & $1 / 4$ & $1 / 3$ & $1 / 2$ & 1 & 2 & 3 & 4 \\
\hline 4 & $1 / 6$ & $1 / 5$ & $1 / 4$ & $1 / 3$ & $1 / 2$ & 1 & 2 & 3 \\
\hline 3 & $1 / 7$ & $1 / 6$ & $1 / 5$ & $1 / 4$ & $1 / 3$ & $1 / 2$ & 1 & 2 \\
\hline 2 & $1 / 8$ & $1 / 7$ & $1 / 6$ & $1 / 5$ & $1 / 4$ & $1 / 3$ & $1 / 2$ & 1 \\
\hline 1 & $1 / 9$ & $1 / 8$ & $1 / 7$ & $1 / 6$ & $1 / 5$ & $1 / 4$ & $1 / 3$ & $1 / 2$ \\
\hline
\end{tabular}

scale, mean a preference or dominance of one use over another for value 3 , that is, moderate. With differences equivalent to two intervals, the dominance would be value 5 , for three intervals 7 , and for four 9 . Intermediate situations will correspond with dominance associated with even values on the Saaty scale.

Based on this approach, the matrices are programmed in Excel using the IF function. Figure 4(a) shows, as an example, one of the 25 matrices constructed for the CR5 criteria.
The assessments made are introduced from the datasheets in the left-hand column and the upper column. Based on this information, and thanks to its programming, the matrices are autocompleted. They then multiply by themselves until the value of the priority vector is stabilised, following the same procedure described for the above comparison matrices. Figure 4(b) shows the result obtained in the fifth iteration of the process for the CR5-2 matrix.

This procedure is followed to construct the matrices of the 11 CR5 criteria associated with the asset analysed and the 14 matrices of the CR5 criteria associated with its setting. Once the priority vectors of each of them have been obtained, the fundamental matrix of preferences is obtained, formed from the preference vectors obtained for each one of the 25 CR5 criteria in relation to the uses considered as alternatives. The fundamental matrix is shown in Table 6.

Finally, based on the scores given for the CR5 criteria, the distribution of preferences for the uses considered is obtained. Figure 5 shows the final preference vector as a spider chart. Thus, for the scores of that fictitious example, the methodology would identify Use 3, sport, as the most compatible with the characteristics of the asset analysed. This distribution of the preferences obtained for the uses considered comes from working the fundamental matrix, which shows the demand relating to each use of the characteristics 


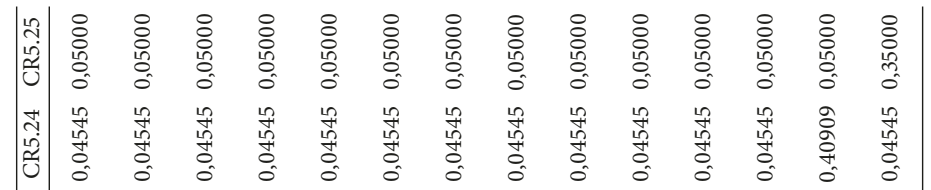

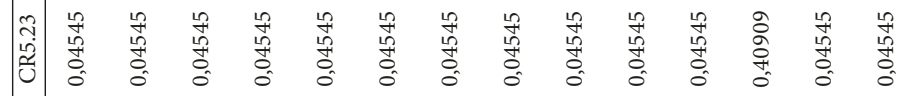

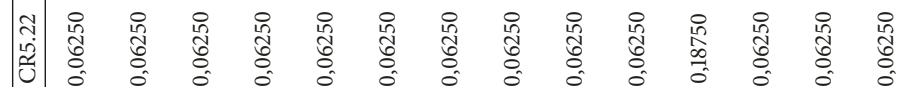

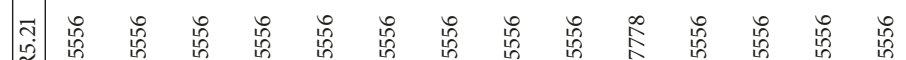

先

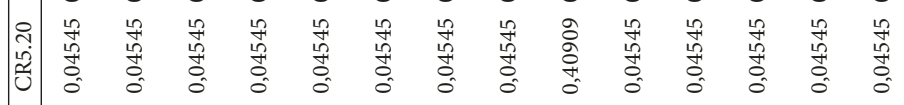

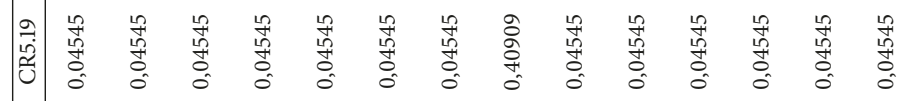

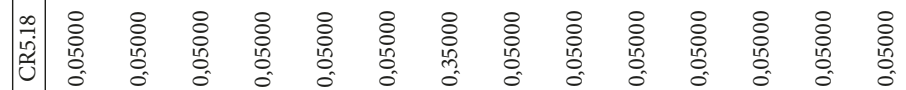

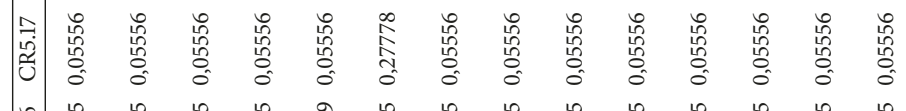

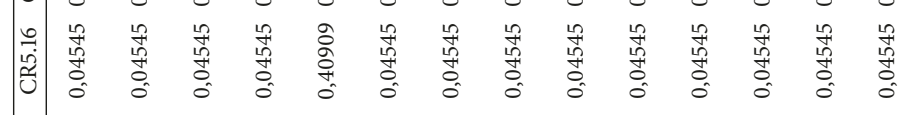

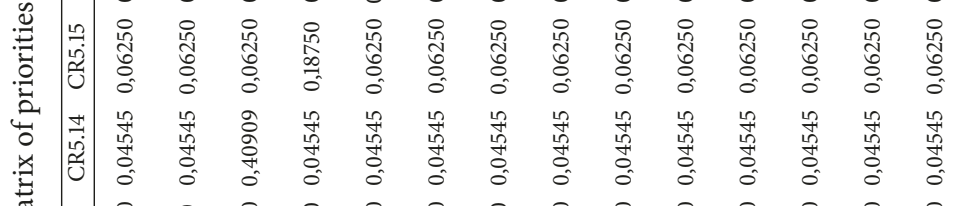

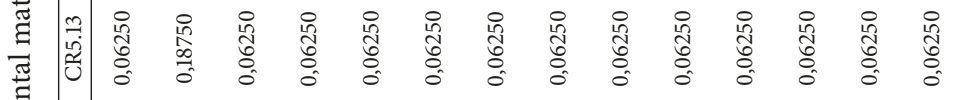

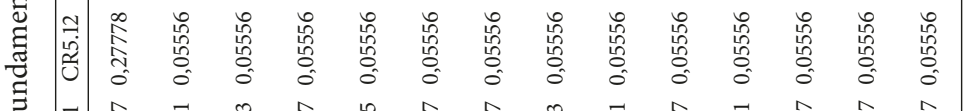

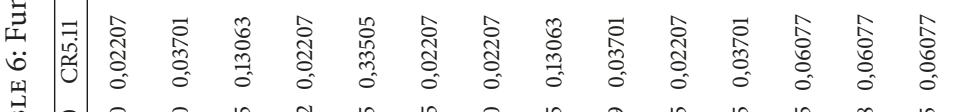

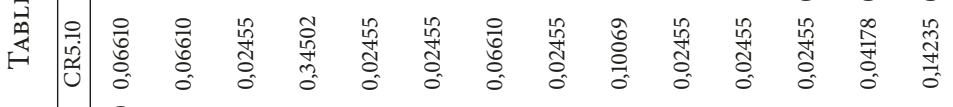

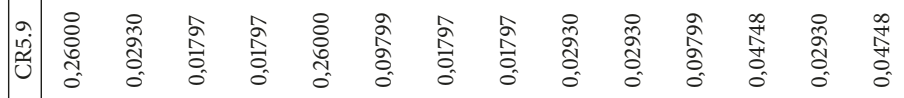

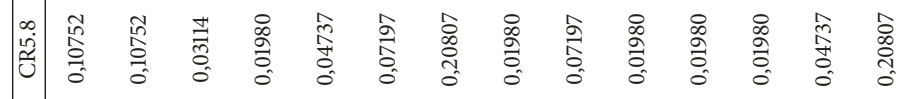

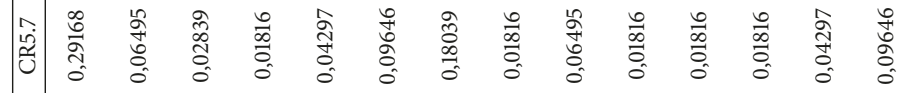

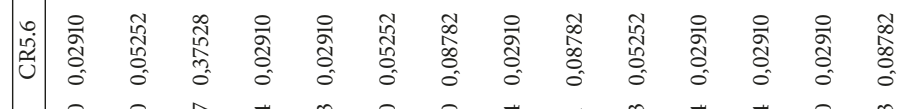

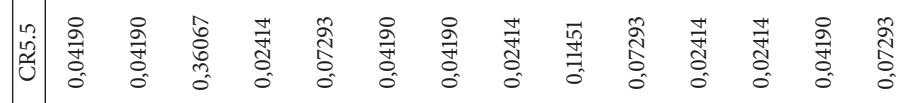

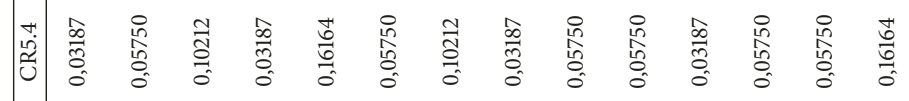

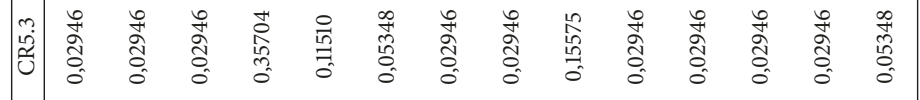

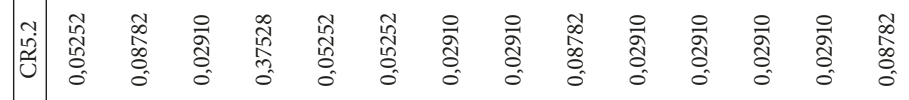

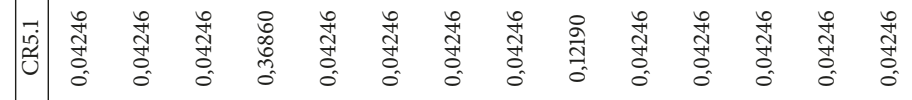

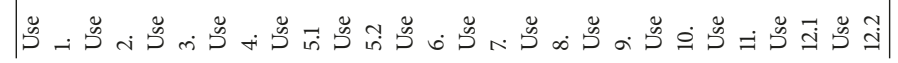




\begin{tabular}{|l|l|}
\hline Use 1. & 0,09843583 \\
\hline Use 2. & 0,04962356 \\
\hline Use 3. & 0,16085646 \\
\hline Use 4. & 0,09358641 \\
\hline Use 5.1 & 0,09440683 \\
\hline Use 5.2 & 0,05587727 \\
\hline Use 6. & 0,07216443 \\
\hline Use 7. & 0,03866404 \\
\hline Use 8. & 0,07839890 \\
\hline Use 9. & 0,04646789 \\
\hline Use 10. & 0,03958812 \\
\hline Use 11. & 0,04010872 \\
\hline Use 12.1 & 0,04520417 \\
\hline Use 12.2 & 0,08661738 \\
\hline
\end{tabular}

1

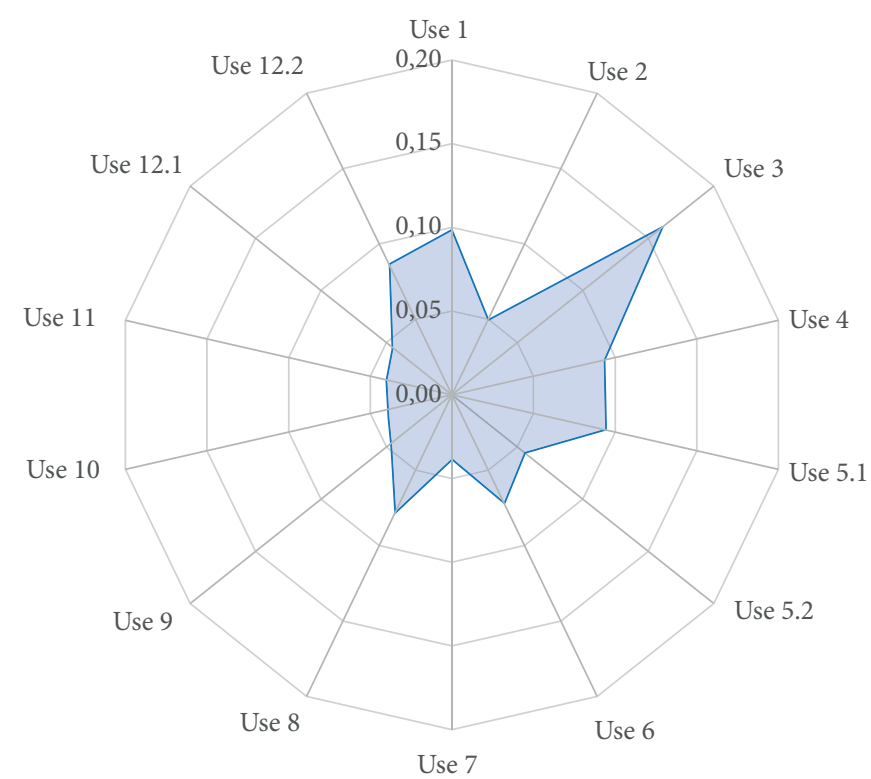

Priority vector

Figure 5: Priority vector for the uses considered and their distribution shown in a spider chart.

represented by the 25 CR5 criteria, by the distribution of weights of these criteria.

\subsubsection{Indirect Compatibility Considering the Impact of the Her-} itage Value. After setting out the structure of criteria responsible for analysing the direct compatibility of the assets being studied with the uses considered, the mechanism proposed for incorporating the impact of the heritage value in the final decision is then set out. As such, the first step is to identify the possible link between the morphological characteristics of the asset, represented by the CR5 criteria, and the characteristics containing the heritage value, represented by the CR 2 criteria, scored using the CR3 in the structure of criteria responsible for the asset heritage assessment. These aspects of interest will be contained in physical parts of the industrial assets analysed. A relationship can therefore be established between the morphological characteristics of CR5 criteria, which materialise in certain physical parts of the asset, and the heritage characteristics of CR2, which may be contained in those parts. Naturally, CR5 criteria related to the institutional study of the setting are not considered, because the heritage characteristics of the assets are not related to the density of uses in its setting, which cannot contain asset heritage value. Table 7 shows the relationships considered in each case.

Having identified the relationships between both groups of criteria, the way in which the value identified in CR2 will affect the weights of CR5 must be defined. If value characteristics exist, the aim is to increase the weight of CR5 associated with the structure of criteria for the selection of new uses. If the weight of a CR5 that is highly demanded for a use versus others increases, that demand will be multiplied, so the preferencing of the characteristic in terms of that use with respect to others will also increase. This also increases its global preference as an alternative, as it demands high weighted characteristics in the structure of criteria. In this way, compatible uses with the characteristic that contain value and that does not demand its adaptation are preferred, avoiding the associated risk.

It is firstly necessary to define how to determine whether or not the value associated with each CR5 criterion on the morphological characteristics of the asset analysed is high; and secondly, how to channel the impact of that value on the updating of the weights of those CR5 criteria. As shown in Table 7, each CR5 criterion is associated with a different number of CR2 criteria. In each case the corresponding CR2 criteria will therefore be analysed from two perspectives. On the one hand, the scores obtained by each of them in the heritage assessment methodology are analysed. And on the other hand, their weight is assessed within the heritage assessment structure of criteria, or, rather, their capacity to contribute value to the particular asset being analysed.

The first approach compares the scores obtained for the CR2 associated with a certain CR5 with those of all the CR2. This provides an illustration in each case of how those scores are within the total group of characteristics assessed for heritage purposes. Based on the scores given to all the CR2 criteria, the methodology defines three intervals: high, medium, and low scores. So, for each CR5 the associated CR2 scores are considered, their mean is obtained, and the interval in which it is located is identified. This analysis is therefore independent of the criteria for the industrial approach of the methodology, trying to identify relevant aspects of the asset without taking its nature into account.

Similarly, for each CR5 criterion, the contribution of heritage value that takes place through the associated CR2 is analysed. Once again, the contribution of all CR2 criteria is 


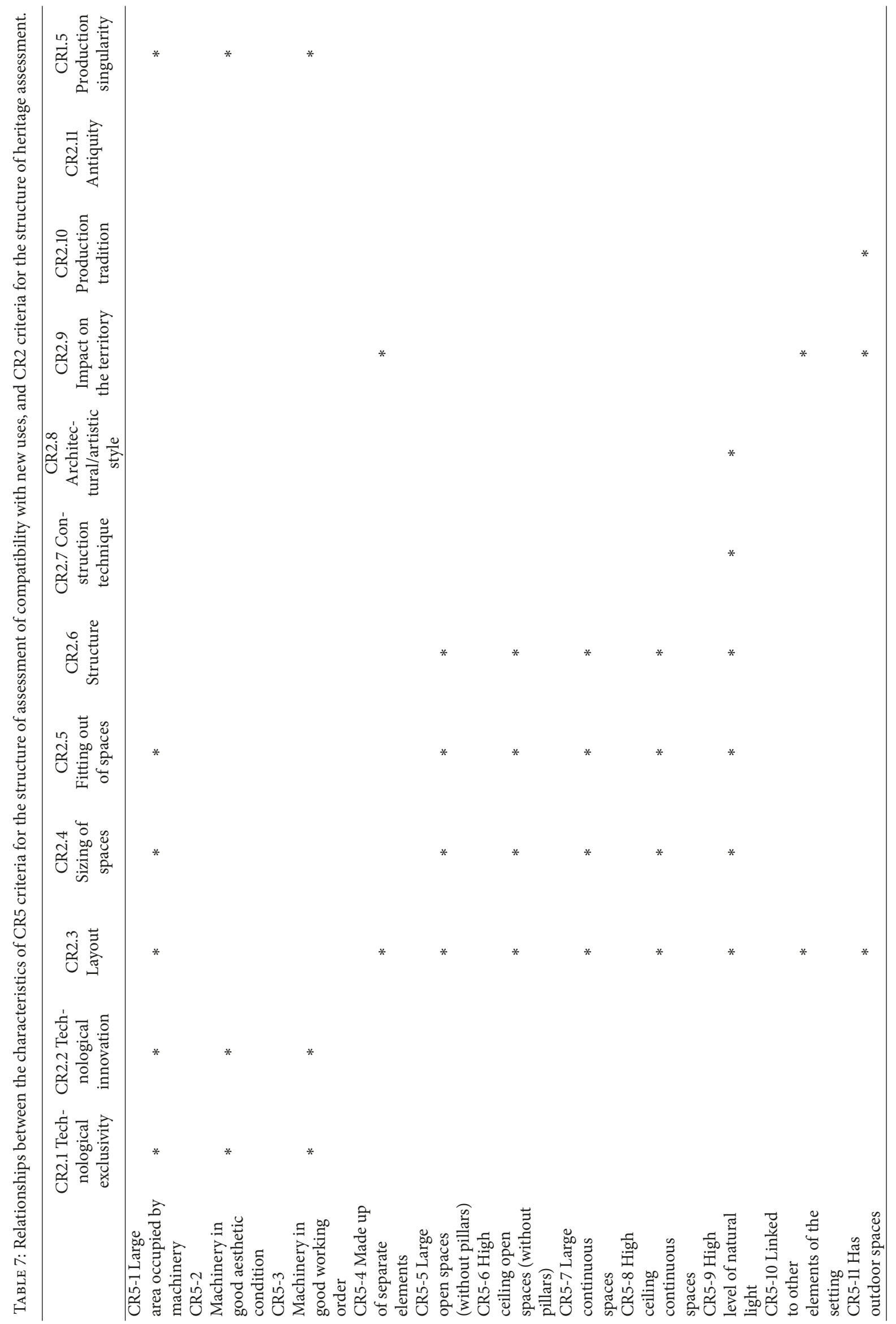




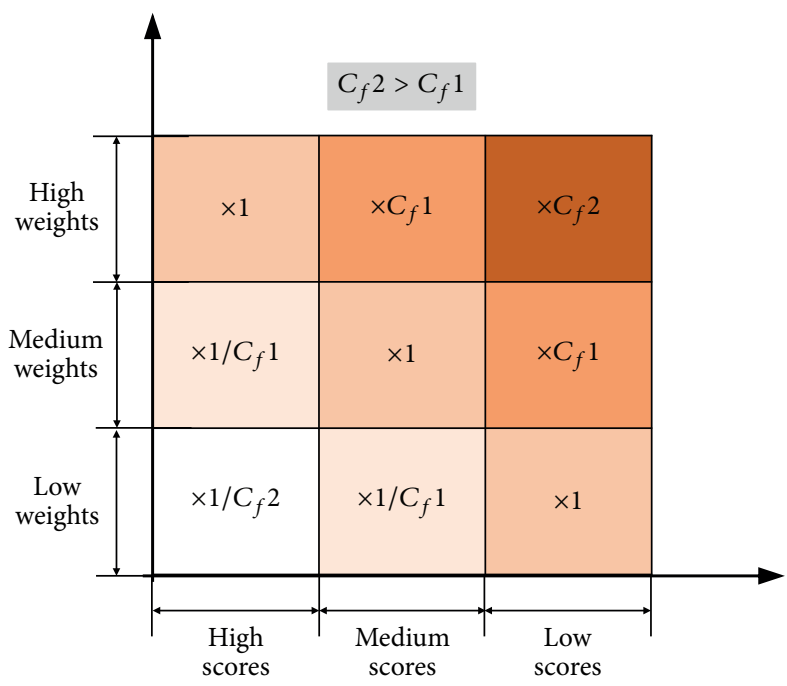

(a)

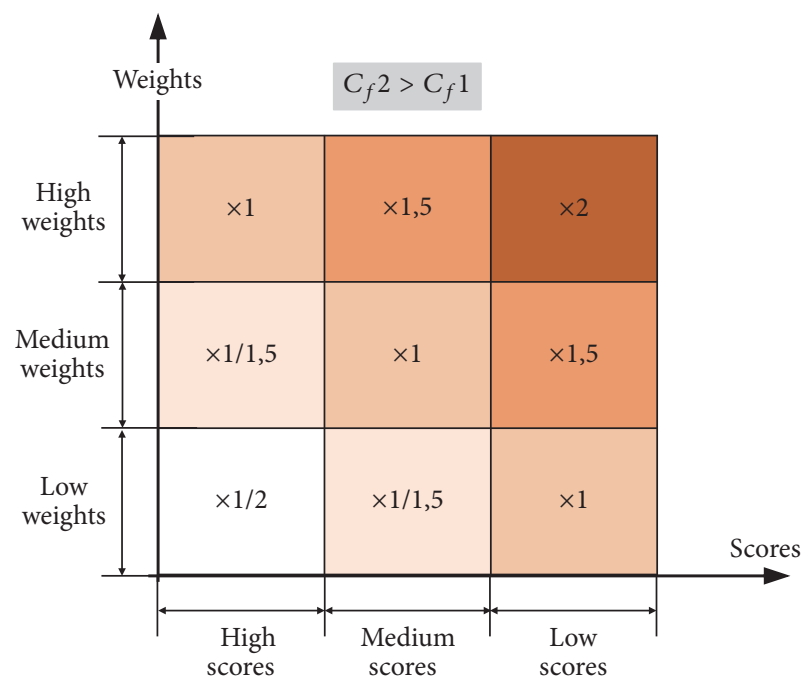

(b)

FIGURE 6: Coefficient matrix affecting the heritage value in CR5 criteria.

considered. This contribution is reflected in the weight that they have in the structure of criteria after the characteristics they represent have been scored for the asset analysed. Thus, considering the weighted weight of all the CR2, three intervals are again established, from the lowest weight identified to the highest weight. For each CR5, the mean weight of the CR2 associated with it is obtained and its belonging to one of the three value intervals is identified.

This twofold analysis makes it possible to identify the relevance of the CR2 heritage characteristics, which in each case are linked to a CR5 regarding the set of heritage characteristics studied. Combining both approaches, it is possible to locate the heritage characteristics of the CR2 linked to a certain CR5 within a three-by-three classification matrix of 9 possible scenarios. If, for both approaches, the characteristics are in the interval of high values, the heritage characteristics associated with that CR5, regarding the rest of the asset heritage characteristics, are noteworthy. The opposite situation would be that in both approaches the characteristics were in the intervals of lesser relevance. Likewise, intermediate situations can be defined between both extremes. Figure 6(a) shows the classification matrix.

This analysis makes it possible to associate belonging to a group within the classification matrix with a level of relevance. In turn, that relevance is associated with a coefficient that will act on the associated CR5 criteria to correct its weight in the structure of criteria, thus introducing the impact of the heritage value. Figure $6(\mathrm{~b})$ shows the coefficients selected in this study. The use of the highest or lowest coefficients would mean increasing or decreasing the impact of the heritage value in the final decision. Figure 7 shows the structure of criteria to select the new use.

As shown in Figure 7, based on the scores given to CR5 criteria associated with both the asset analysed and its setting, a first distribution of the preferences for uses considered as alternatives is made. This first preferencing of uses corresponds to the direct compatibility already described. The impact of the heritage value is subsequently incorporated in the final decision. Figure 7 shows how this process only affects CR5 criteria associated with the asset, not those of the setting, as already previously justified. Figure 8 shows a partial and enlarged view of the structure of criteria. As regards each CR5, how the corresponding CR2 are analysed under the two approaches described and the appropriate correction coefficient selected, based on the classification matrix, can be seen. Once the impact of the heritage value associated with each CR5 criterion is incorporated and their weights in the criteria structure are corrected, the values are normalised.

Thus, when the fundamental matrix illustrated in Table 7 operates on the distribution of weights of the 25 CR5 criteria, the value of these weights includes the impact of the heritage value identified in the proposed heritage assessment methodology. The preference vector ultimately obtained, therefore, differs from that which the criteria structure returned before incorporating the heritage value in the decision, which was shown in Figure 5. CR5 criteria associated with CR2 criteria with heritage value increase their weight in the structure and, therefore, the preference for compatible uses with those characteristics, which are those that best protect them as modifications, is not required. In turn, loss of weight in the structure of CR5 criteria not associated with value characteristics will enable uses not compatible with those CR5 to gain weight as alternatives. This corresponds to the possibility of modifying the morphological characteristics of those CR5 criteria without heritage value.

As shown in Figure 9, the distributions of preferences for new uses that will be obtained, considering and not considering the impact of the heritage value, will not be conflicting. The effect of the heritage value will influence the decision, increasing some preferences and decreasing others. 


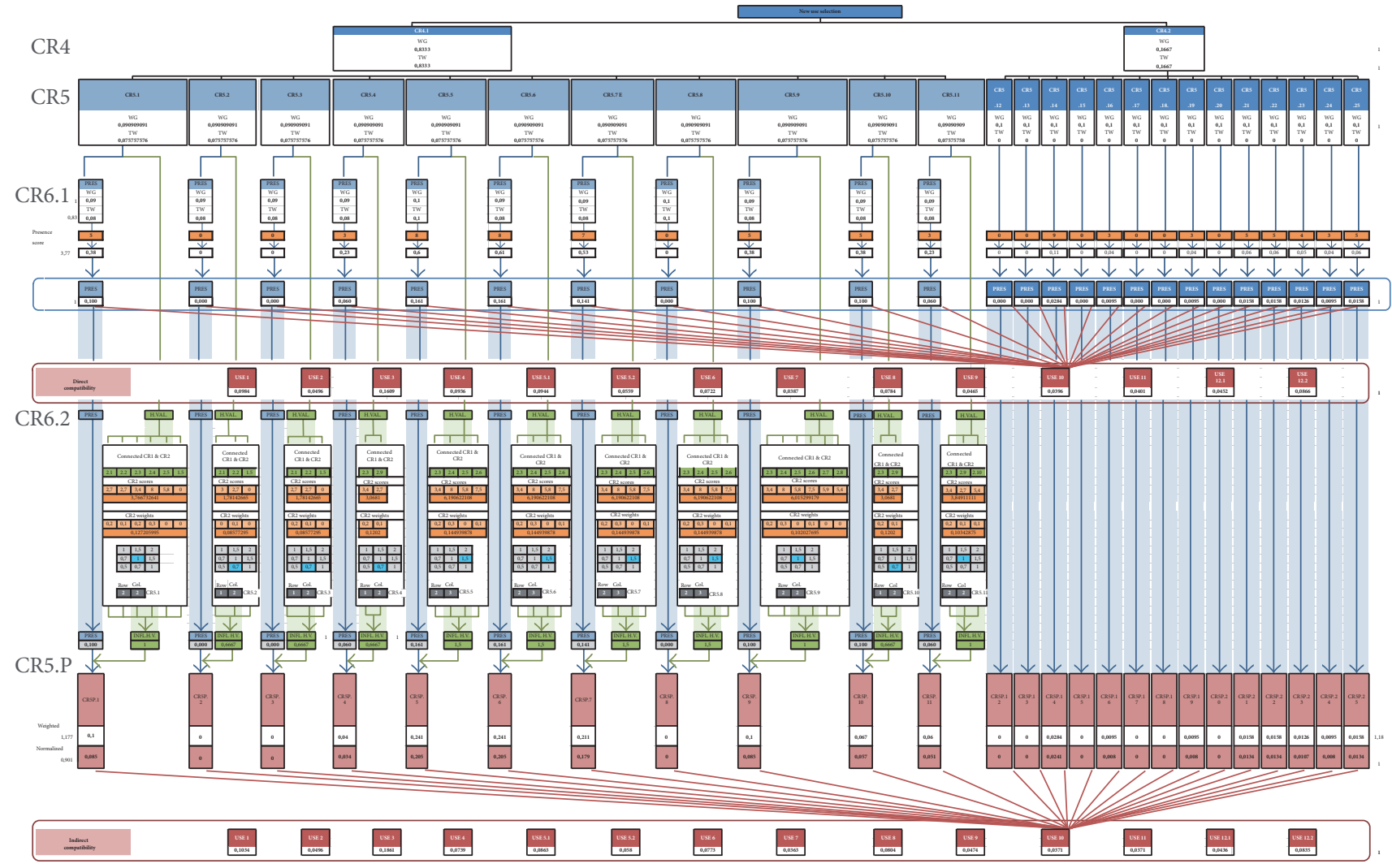

FIGURE 7: Hierarchical structure of criteria for selection of new uses.

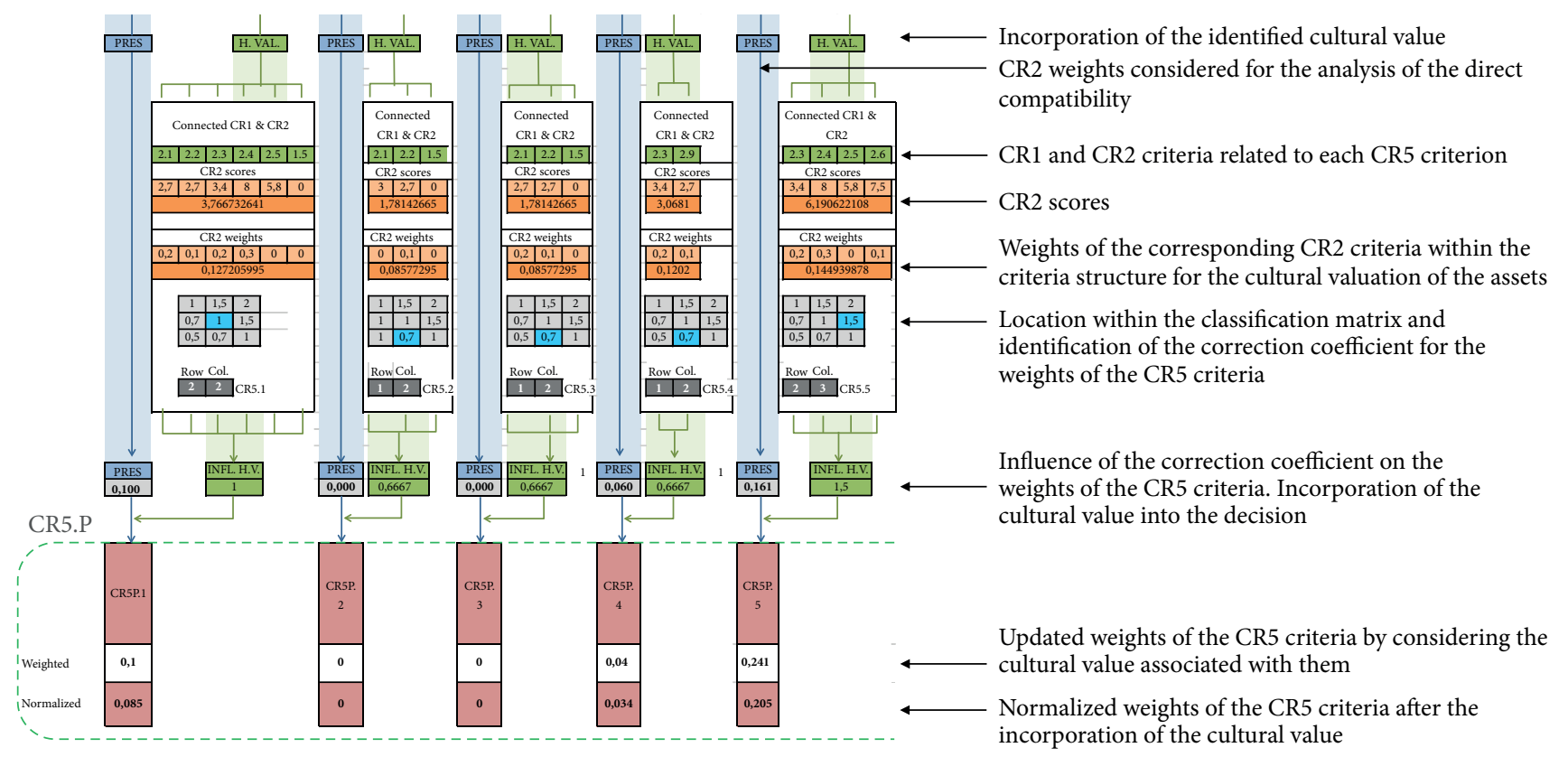

FIGURE 8: Partial view of the hierarchical structure of criteria for selection of new uses. 
Fundamental matrix

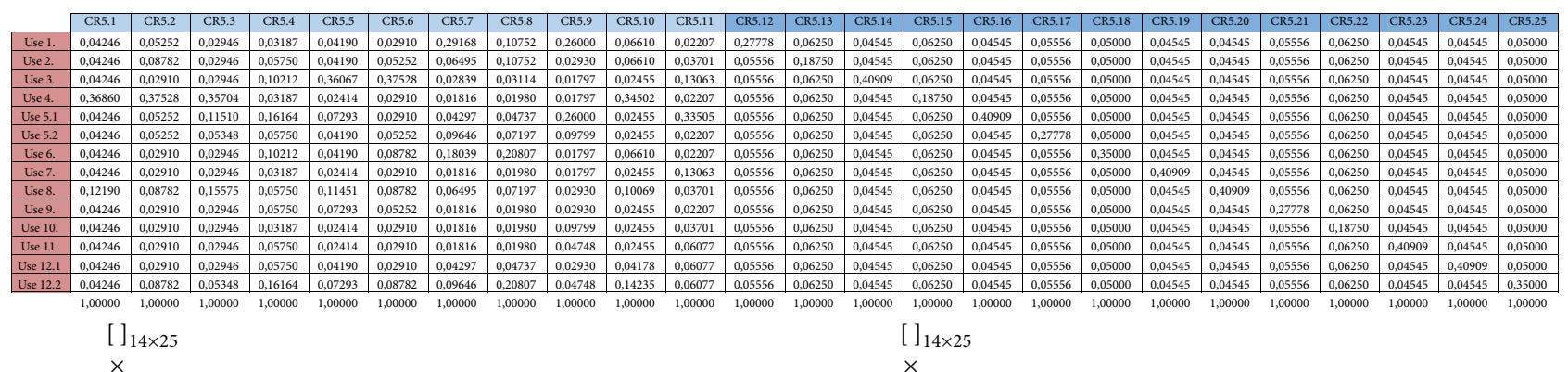

\begin{tabular}{|l|l|}
\hline CR5.1 & 0,10037281 \\
\hline CR5.2 & 0,00000000 \\
\hline CR5.3 & 0,00000000 \\
\hline CR5.4 & 0,06022369 \\
\hline CR5.5 & 0,16059650 \\
\hline CR5.6 & 0,16059650 \\
\hline CR5.7 & 0,14052194 \\
\hline CR5.8 & 0,00000000 \\
\hline CR5.9 & 0,10037281 \\
\hline CR5.10 & 0,10037281 \\
\hline CR5.11 & 0,06022369 \\
\hline CR5.12 & 0,00000000 \\
\hline CR5.13 & 0,00000000 \\
\hline CR5.14 & 0,02839117 \\
\hline CR5.15 & 0,00000000 \\
\hline CR5.16 & 0,00946372 \\
\hline CR5.17 & 0,00000000 \\
\hline CR5.18 & 0,00000000 \\
\hline CR5.19 & 0,00946372 \\
\hline CR5.20 & 0,00000000 \\
\hline CR5.21 & 0,01577287 \\
\hline CR5.22 & 0,01577287 \\
\hline CR5.23 & 0,01261830 \\
\hline CR5.24 & 0,00946372 \\
\hline CR5.25 & 0,01577287 \\
\cline { 2 - 2 } &
\end{tabular}

Weights of the CR 5 criteria without considering the influence of the heritage value

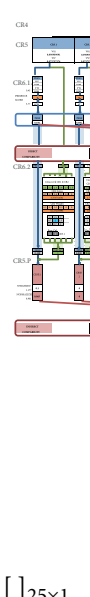

Priority vector for new uses without considering the cultural value

\begin{tabular}{|c|l|}
\hline Use 1. & 0,09843583 \\
\hline Use 2. & 0,04962356 \\
\hline Use 3. & 0,16085646 \\
\hline Use 4. & 0,09358641 \\
\hline Use 5.1 & 0,09440683 \\
\hline Use 5.2 & 0,05587727 \\
\hline Use 6. & 0,07216443 \\
\hline Use 7. & 0,03866404 \\
\hline Use 8. & 0,07839890 \\
\hline Use 9. & 0,04646789 \\
\hline Use 10. & 0,03958812 \\
\hline Use 11. & 0,04010872 \\
\hline Use 12.1 & 0,04520417 \\
\hline Use 12.2 & 0,08661738 \\
\hline & 1 \\
\hline
\end{tabular}

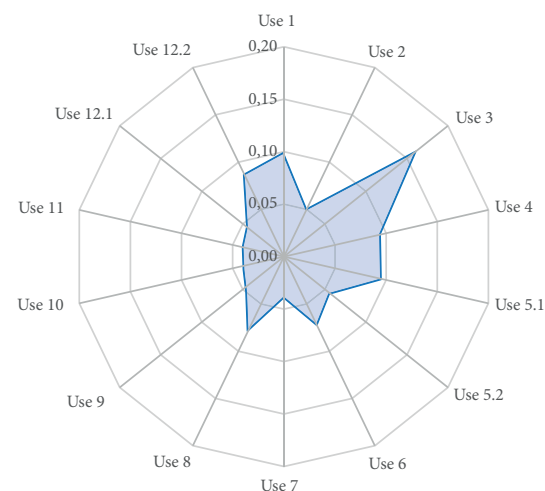

Use 7 $\times$

\begin{tabular}{|l|l|}
\hline CR5.1 & 0,08525495 \\
\hline CR5.2 & 0,00000000 \\
\hline CR5.3 & 0,00000000 \\
\hline CR5.4 & 0,03410198 \\
\hline CR5.5 & 0,20461189 \\
\hline CR5.6 & 0,20461189 \\
\hline CR5.7 & 0,17903540 \\
\hline CR5.8 & 0,00000000 \\
\hline CR5.9 & 0,08525495 \\
\hline CR5.10 & 0,05683664 \\
\hline CR5.11 & 0,05115297 \\
\hline CR5.12 & 0,00000000 \\
\hline CR5.13 & 0,00000000 \\
\hline CR5.14 & 0,02411497 \\
\hline CR5.15 & 0,00000000 \\
\hline CR5.16 & 0,00803832 \\
\hline CR5.17 & 0,00000000 \\
\hline CR5.18 & 0,00000000 \\
\hline CR5.19 & 0,00803832 \\
\hline CR5.20 & 0,00000000 \\
\hline CR5.21 & 0,01339721 \\
\hline CR5.22 & 0,01339721 \\
\hline CR5.23 & 0,01071777 \\
\hline CR5.24 & 0,00803832 \\
\hline CR5.25 & 0,01339721 \\
\cline { 2 - 2 } &
\end{tabular}

Weights of the CR5 criteria considering the influence of the heritage value

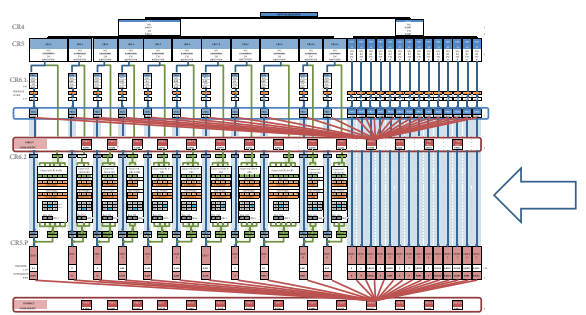

Priority vector for new uses considering the cultural value

\begin{tabular}{|c|c|}
\hline Use 1. & 0,10343676 \\
\hline Use 2. & 0,04960620 \\
\hline Use 3. & 0,18607864 \\
\hline Use 4. & 0,07385706 \\
\hline Use 5.1 & 0,08625707 \\
\hline Use 5.2 & 0,05797944 \\
\hline Use 6. & 0,07728773 \\
\hline Use 7. & 0,03631400 \\
\hline Use 8. & 0,08042419 \\
\hline Use 9. & 0,04743101 \\
\hline Use 10. & 0,03709891 \\
\hline Use 11. & 0,03710411 \\
\hline Use 12.1 & 0,04363466 \\
\hline Use 12.2 & 0,08349022 \\
\hline & \multicolumn{2}{|r}{1} \\
\hline
\end{tabular}

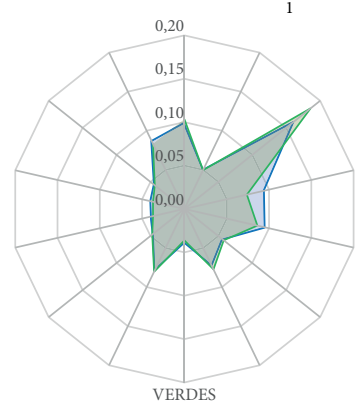

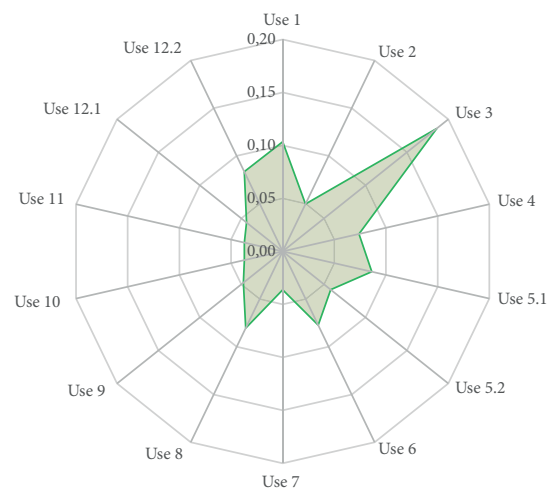

FIgURE 9: Preferences for new uses with and without impact of the heritage value. 
However, the asset analysed is the same in both cases, so evidently it is not possible to talk about radical trend changes.

\section{Case Study Results}

For their validation, the proposed methodologies have been applied to different real case studies. Set out below is an example of the application of one of the warehouses of the Richard Gans Printing Works in Madrid. The score required by the methodology of the CR2 and CR5 criteria to offer results requires a physical visit to the asset analysed and its thorough preliminary study. As is logical, outlining this previous phase would excessively extend the explanation of this study. However, as indicated above, the aim is to consider the proposed methodologies as tools, promoting their use in the study and management of these types of assets. That is why a description is provided in this section of the datasheets of results that the methodology generates automatically when entering the scores for CR2 criteria and CR3 criteria during the analysis of a real case study. Figure 10 shows the three datasheets of results generated automatically by the methodology for the asset selected.

The proposed methodologies are capable of generating results through the structures of criteria described in the previous sections. The criteria they incorporate and the hierarchies established between them have an effect on the scores that the user is asked to enter for a number of characteristics. But the interface which the user uses does not correspond to those structures, but rather to the datasheets shown in Figure 10. Figure 10(a) shows the datasheet of results for the heritage assessment methodology, while Figures 10(b) and 10 (c) show the datasheets resulting from the methodology for the selection of new uses. The areas of the datasheets where the user must enter the scores requested are highlighted in red and marked with an asterisk. They are used to generate real-time result graphs. Generally, spider and bar charts that are considered complementary for their interpretation by different users are combined. These charts are intended to aid interpretation of the results and are briefly described in Figure 10.

At the top of the first datasheet, shown in Figure 10(a), information is included on the catalogue of assets produced in the first of the three partial methodologies developed [1] and which is not covered by this study. This information helps in contextualising the asset analysed in the catalogue produced and therefore in the sample of assets of this type identified in Spain.

In the same datasheet, to the right of the scores requested for the CR2 criteria, the distribution of weights for the element analysed is shown in both a spider and a bar chart. This distribution is compared to that obtained for a situation of maximum scores for all the criteria scored and with the preferencing of criteria established under the study approach, which prioritises aspects of a greater industrial nature. The bottom part shows firstly the 3 scores given to each CR2 criterion relative to their interest, current state, and geographical singularity. The trend of the scores relative to the interest given to each CR2 is then compared with the weight of the criteria once weighted.
In Figure 10(b), under the scores for the CR5 criteria, the distribution of weights of these criteria, after entering their scores, is shown as a spider chart. Both the weights of the CR5 criteria relative to the asset analysed and its setting are represented jointly on the left-hand side. They are shown separately on the right. At the bottom of this datasheet the same analysis is shown as a bar chart. The distribution of weights of CR5 criteria considering the heritage value identified and without considering it is compared at the top of Figure 10(c).

Various spider charts on the preferencing of uses are included under this bar chart. These charts show the main result of the proposed methodology. They firstly show the preferences for possible uses, both excluding the impact of the heritage value on the decision and incorporating it. Both representations are completed with a representation that overlaps both distributions and allows us to see which uses increase their preference and which diminish it. Finally, at the bottom of the datasheet, both analyses are repeated, but independently representing the preferencing of uses obtained from the CR5 criteria relative to the asset analysed and those relative to its setting. This visualisation is useful when the distribution of preferences does not mark a single use as an outstanding alternative. In such cases, visualising the needs of the setting independently can help in making the final decision.

\section{Discussion}

The proposed methodologies, applied both independently and jointly, help in resolving various problems that the management of industrial assets has revealed in recent years. The adaptation of the AHP to the study of these assets has allowed simultaneous consideration of many aspects of a very different nature that must be taken into account in the decision-making process in this field. The hierarchical structures proposed have made it possible to prioritise aspects of a greater industrial nature in the analysis of this typology, which is consistent with the origin of these assets, although that has not always been the case when acting on them. Incorporating the heritage value in the structure of criteria designed to select new uses helps in identifying those that most respect the heritage value and, therefore, that are more compatible with its conservation. This is the achievement of the main objective of this study.

In addition, the automatic generation of result datasheets helps in enhancing the role of work tools that the proposed methodologies are intended to have. Both the methodologies and results obtained have been presented to those responsible for the National Industrial Heritage Plan of the Spanish Cultural Heritage Institute, which reports to the Ministry of Education, Culture and Sport. This body has recognised the interest of the proposals described in this study and it has selected them under its Cycle of Conferences on Good Industrial Heritage Practices.

The authors are currently analysing ways of developing a computer application that channels the use of the proposed methodologies, as well as new methodology developments. In that sense two main work lines have been defined. On the one hand a massive application of the exposed methodology wants to be applied to the assets included in the extensive 
(a)

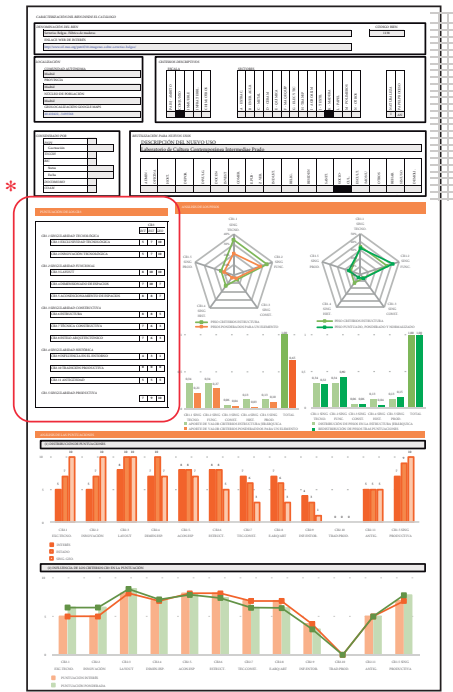

(b)

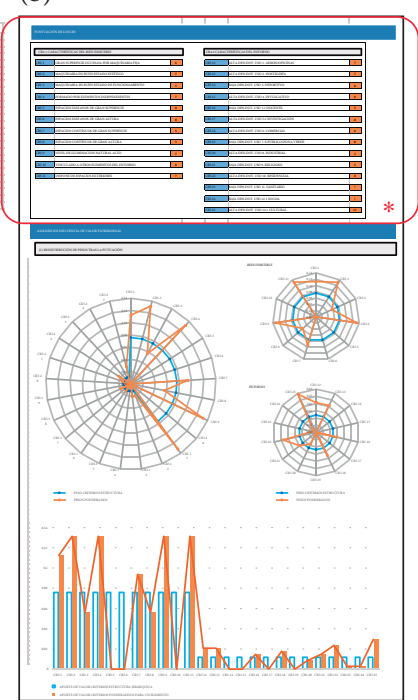

(c)

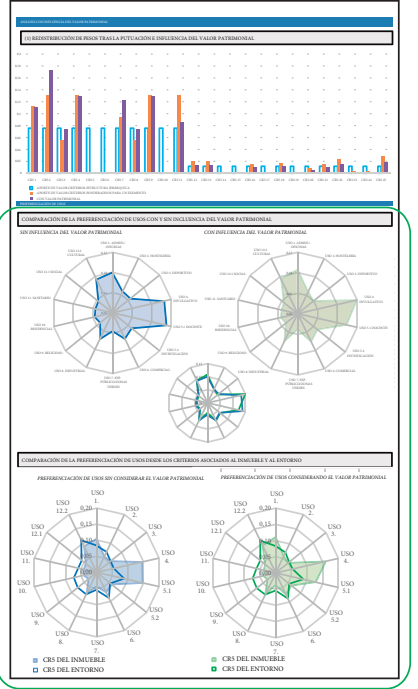

Preference for new uses considering and without considering the heritage value

Without considering the heritage value Considering the heritage value
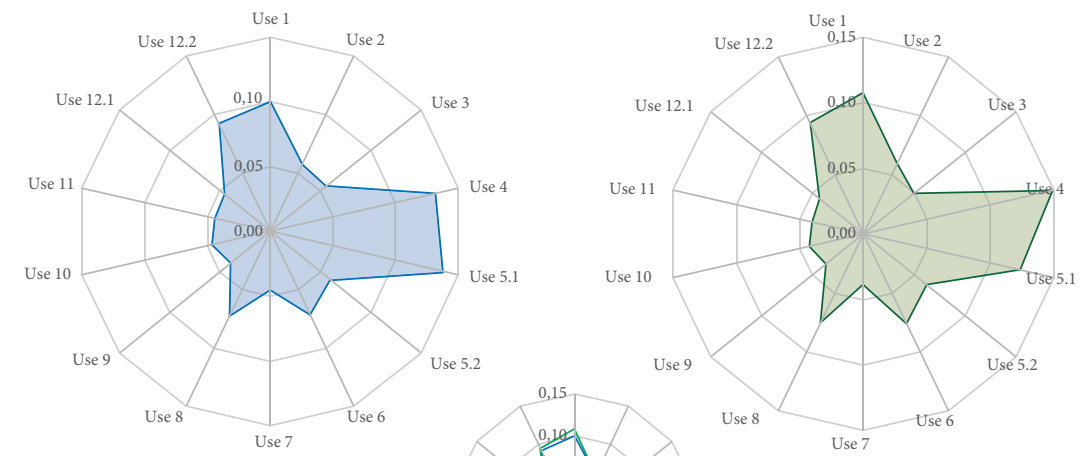

业
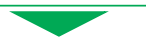
catalogue developed by the authors. The potential that then the criteria structure has as a tool for the management of the assets of this typology in a particular area is considered of great interest. And, on the other hand, the authors are working on new developments of the methodology that allow multiobjective optimisation to be incorporated into new use adaptation proposals.

\section{Conflicts of Interest}

There are no conflicts of interest related to this paper.

\section{References}

[1] J. Claver, Methodology for the analysis and interpretation of the assets of the Spanish industrial heritage. Application to the study of the assets of the Autonomous Community of Madrid [Ph.D. thesis], Universidad Nacional de Educación a Distancia, 2016.

[2] M. Velasquez and P. T. Hester, "An analysis of multi-criteria decision making methods," International Journal of Operations Research, vol. 10, no. 2, pp. 56-66, 2013.

[3] B. Ceballos, M. T. Lamata, and D. A. Pelta, "A comparative analysis of multi-criteria decision-making methods," Progress in Artificial Intelligence, vol. 5, no. 4, pp. 315-322, 2016.

[4] K. M. A.-S. Al-Harbi, "Application of the AHP in project management," International Journal of Project Management, vol. 19, no. 1, pp. 19-27, 2000.

[5] M. Khodaei Tehrani, A. Fereidunian, and H. Lesani, "Financial planning for the preventive maintenance of power distribution systems via fuzzy AHP," Complexity, vol. 21, no. 3, pp. 36-46, 2016.

[6] J. Ren, D. Xu, H. Cao, S. Wei, L. Dong, and M. E. Goodsite, "Sustainability decision support framework for industrial system prioritization," AIChE Journal, vol. 62, no. 1, pp. 108-130, 2016.

[7] M. Hosseini Firouz and N. Ghadimi, "Optimal preventive maintenance policy for electric power distribution systems based on the fuzzy AHP methods," Complexity, vol. 21, no. 6, pp. 70-88, 2016.

[8] R. Venkata, Decision Making in the Manufacturing Environment Using Graphic Theory and Fuzzy Multiple Attribute DecisionMaking Methods, Soringer, London, UK, 2013.

[9] E. S. Bakhoum and D. C. Brown, "A hybrid approach using AHP-TOPSIS-entropy methods for sustainable ranking of structural materials," International Journal of Sustainable Engineering, vol. 6, no. 3, pp. 212-224, 2013.

[10] S. Balli and S. Korukoǧlu, "Development of a fuzzy decision support framework for complex multi-attribute decision problems: a case study for the selection of skilful basketball players," Expert Systems with Applications, vol. 31, no. 1, pp. 56-69, 2014.

[11] T. L. Saaty, The Analytic Hierarchy Process, McGraw-Hill, New York, NY, USA, 1980.

[12] T. Saaty and L. Vargas, Models, methods, concepts \&amp; applications of the Analytic Hierarchy Process, Springer, New York, NY, USA, 2012.

[13] S. Attaran and B. Gokhan, "Analytic Hierarchy Process: An Application in Green Building Market Research," International Review of Management and Marketing, vol. 3, no. 3, pp. 122-133, 2013.

[14] A. Cerqua, E. Gigliarelli, and L. Cessari, "Application of the Analytic Hierarchy Process (AHP) for energetic rehabilitation of historical buildings," in Proceedings of the 11th International Symposium on Analytic Hierarchy Process, Sorrento, Italy, 2011.

[15] Z. Yaolin, "An application of the AHP in cultural heritage conservation strategy for China," Canadian Social Science, vol. 2, no. 3, pp. 16-20, 2006, http://dx.doi.org/10.3968/j.css .1923669720060203 .002 .

[16] J. Macías Bernal, J. Calama Rodríguez, and M. J. Chávez de Diego, "Modelo de predicción de la vida útil de la edificación patrimonial a partir de la lógica difusa," Informes de la construcción, vol. 66, no. 533, pp. 1-11, 2014.

[17] P. Aragonés-Beltrán, J. Aznar Bellver, J. M. Ferris-Oñate, and M. García-Melón, "Valuation of urban industrial land: An analytic network process approach," European Journal of Operational Research, vol. 185 , no. 1, pp. 322-339, 2008, https://doi.org/10 $.1016 /$ j.ejor.2006.09.076doi.

[18] J. Claver, M. A. Sebastián, and A. Sanz-Lobera, “Opportunities of the multicriteria methods in the study of immovable assets of the Spanish industrial heritage," Procedia Engineering (132), pp. 175-182, 2015.

[19] T. L. Saaty, "The analytic hierarchy and analytic network processes for the measurement of intangible criteria and for decision-making," in Multiple Criteria Decision Analysis: State of the Art Surveys, vol. 78, International Series in Operations Research \&amp; Management Science, New York, NY, USA, 2005.

[20] T. L. Saaty and L. G. Vargas, Decision Making with the Analytic Network Process, Springer, 2006.

[21] J. Claver-Gil, M. Á. Sebastián-Pérez, and L. Sevilla-Hurtado, "Metodología para el estudio del patrimonio industrial," Aplicación a la Comunidad Autónoma de Andalucía. DYNA, vol. 91, no. 2, pp. 136-139, 2016. 


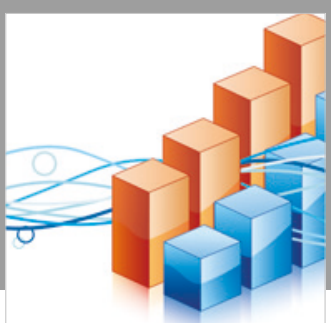

Advances in

Operations Research

\section{-n-m}
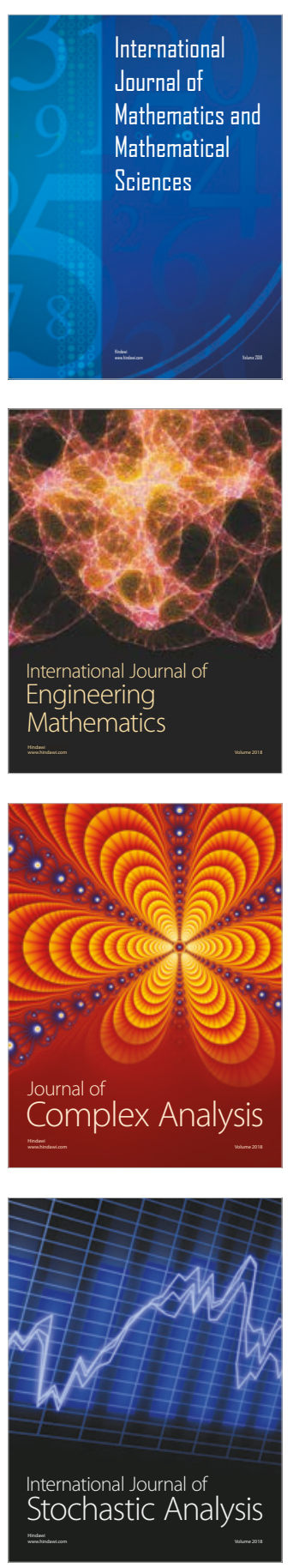
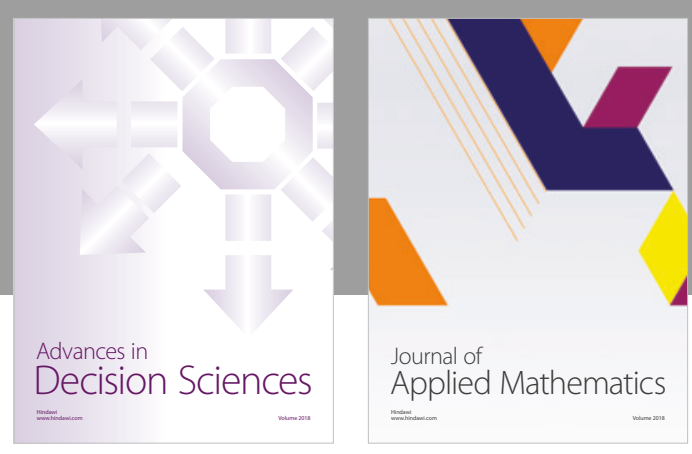

Journal of

Applied Mathematics
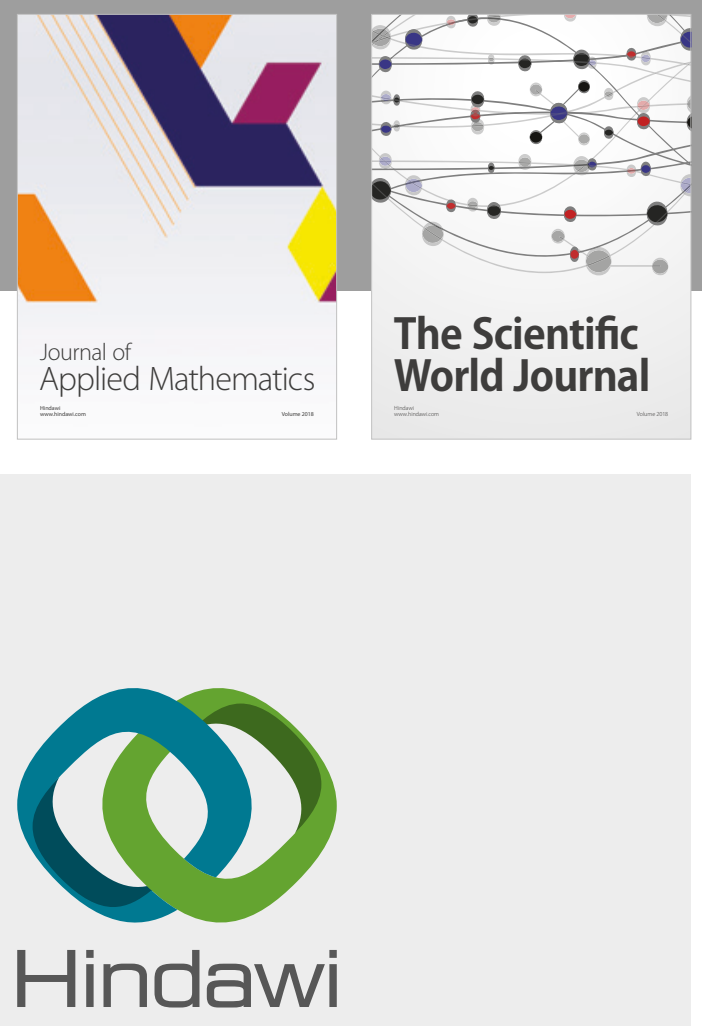

Submit your manuscripts at

www.hindawi.com

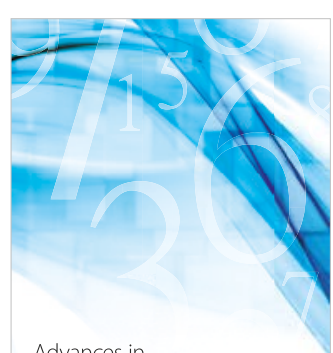

Advances in
Numerical Analysis
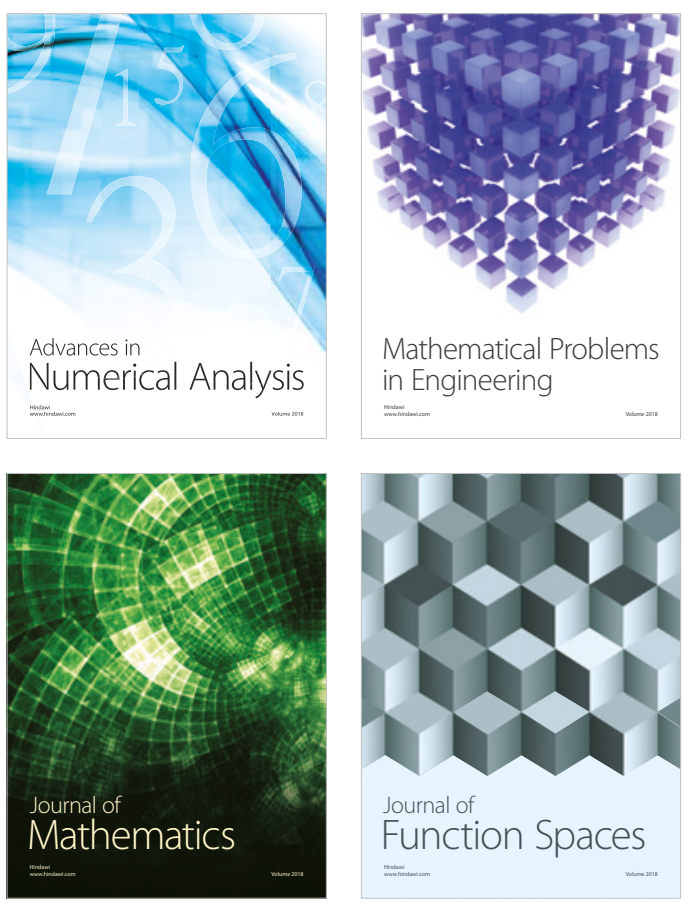

Mathematical Problems in Engineering

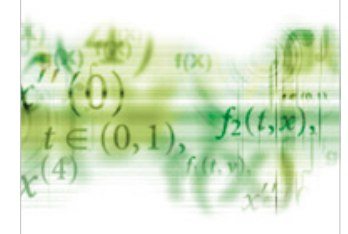

International Journal of

Differential Equations

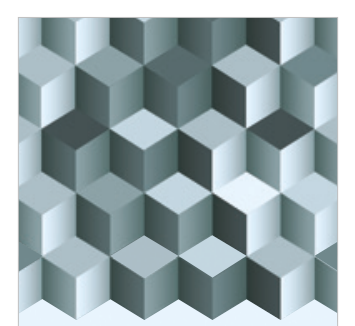

Journal of

Function Spaces
The Scientific

World Journal

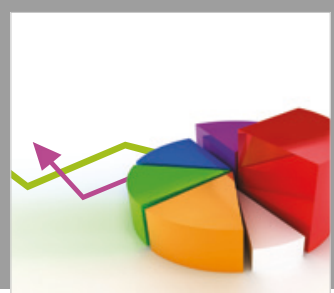

Journal of

Probability and Statistics
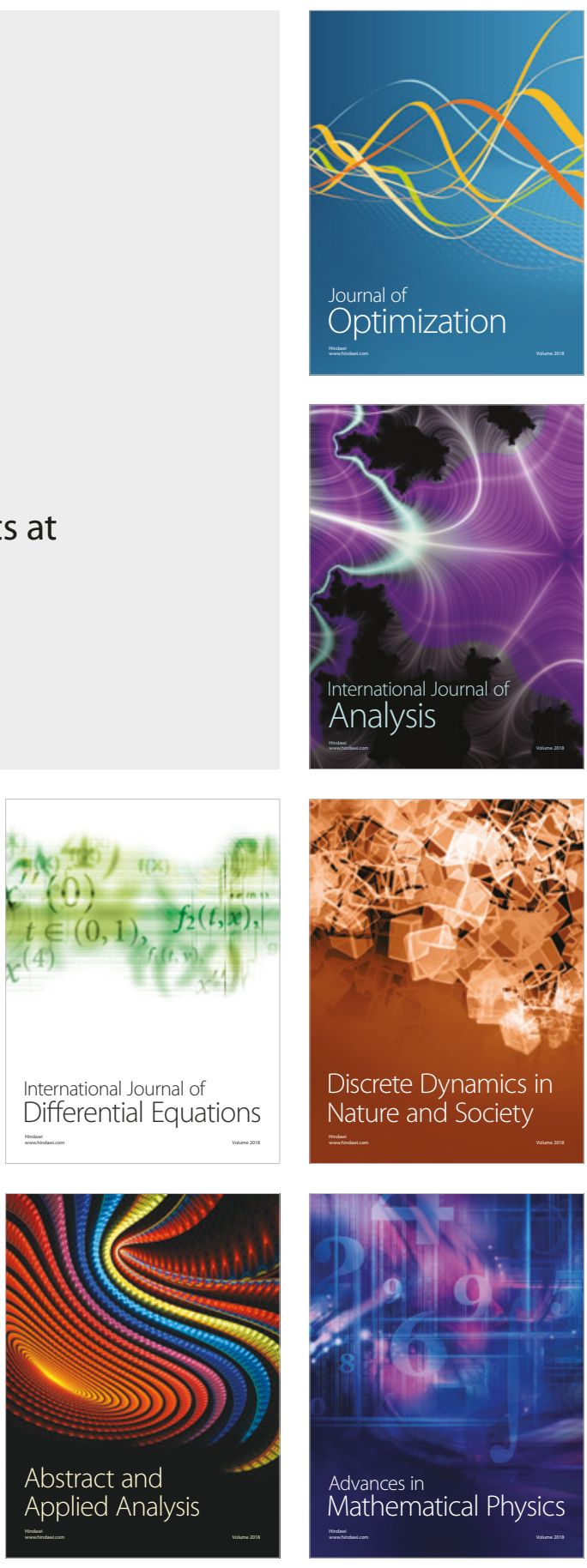